\title{
دراسة مقارنة للاختبارات الدولية TIMSS في كل من سنغافورة وكوريا الجنوبية ومدى إمكانية الإفادة منها في المملكة العربية السعودية
}

\author{
أماني أحمد محمود العقالي \\ مُشرفة تربوية- إدارة تعليم البنات بمحافظة جدة- المملكة العربية السعودية \\ ماجستير من جامعة الملك عبد العزيز-جدة- السعودية \\ باحثة دكتوراه في أصول التربية- جامعة الإمام محمد بن سعود الإسلامية- الرياض- السعودية \\ amaniahmad14011@gmail.com
}




\title{
دراسـة مقارنة للاختبارات الدولية TIMSS في كل من سنغافورة وكوريا الجنوبية ومدى إمكانية الإفادة منها في المملكة العربية السعودية
}

\author{
أماني أحمد محمود العقالي \\ مُشرفة تربوية- إدارة تعليم البنات بمحافظة جدة- المملكة العبية السعودية \\ ماجستير من جامعة الملك عبد العزبز-جدة- السعودية إدهائ \\ باحثة دكتوراه في أصول التربية- جامعة الإمام محمد بن سعود الإسلامية- الرياض- السعودية \\ amaniahmad14011@gmail.com
}

DOI: https://doi.org/10.31559/EPS2021.10.3.11 2021/9/6 2021/6/16 مراجعة البحث: 2021/7/21 قبول البحث

هدف البحث مقارنة الاتجاهات الدولية للرياضيات والعلوم TIMSS في كل من سنغافورة وكوريا الجنوبية وبيان مدى إمكانية الإفادة منها

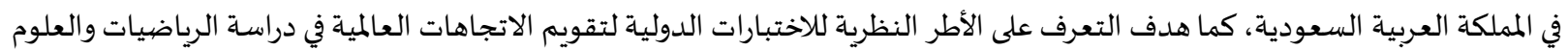
TكS للصفين الرابع والثامن من التعليم الأساسي في كل من سنغافورة وكوريا الجنوبية (دولتي المقارنة) في ضوء القوى والعوامل المؤثرة فيها،

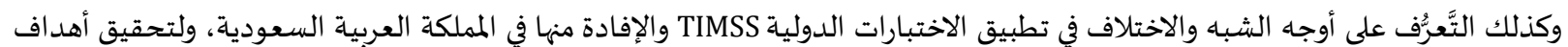

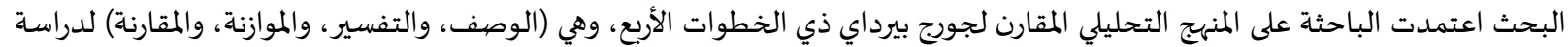

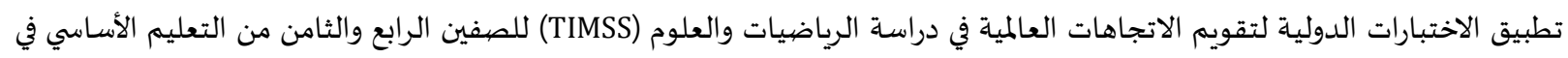
دولتي المقارنة سنغافورة وكوريا الجنوبية في ضوء كل من العامل السياسي، والجغرافي، والسكاني، والثقافي، والاقتصادي، ثم تحديد أوجه

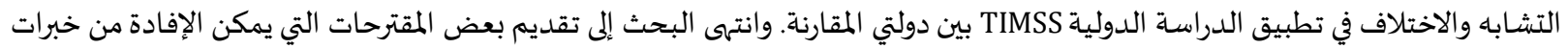
دولتي المقارنة (سنغافورة وكوريا الجنوبية) وتجربتهما في خوض الاختبارات الدولية وتحقيق المراكز المتقدمة، في المملكة العربية السعودية. الكلمات المفتاحية: دراسة الاتجاهات الدولية للرياضيات والعلوم TIMSS؛ الدراسة الدولية، TIMSS؛ سنغافورة؛ كوريا الجنوبية؛ المملكة العربية السعودية.

يُواجه العالم في العصر الحديث عديدًا من التحديات التي تشكل ضغوطًا على مختلف الدول في جميع المجالات، ومن أبرز هذه التحديات

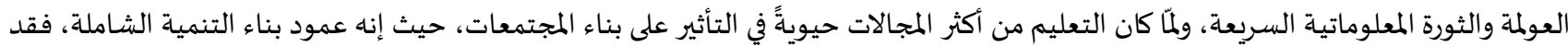

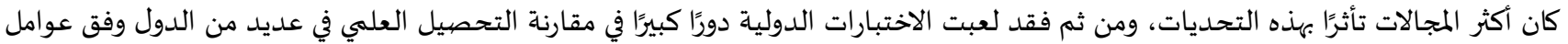

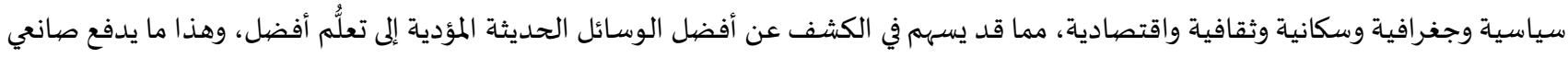
القرار في المجال التعليمي، والمهتمين من الباحثين والأكاديميين إلى معرفة مواطن الخلل في المنظومة التعليمية؛؛ من أجل تحسين مستوى الأداء التعليمي

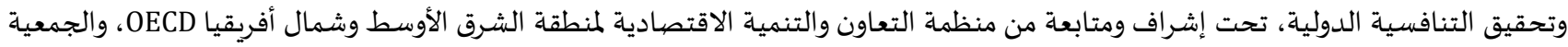

الدولية لتقييم التحصيل التربوي (IEA). 
وقد قامت دراسات عديدة على المستوى العالمي بهدف تحسين وتطوير عملية تعليم الرياضيات والعلوم وتعلُّمها، وكذلك دراسة العوامل التي من شأنها رفع قدرة الطلاب على مواجهة المشكلات التي تصادفهم من خلال تحسين تحصيلهم الدراسي في الرياضيات والعلى العلوم، والإفادة من

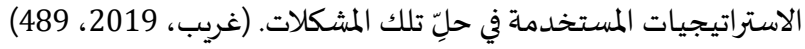
وتشير دراسة (الزعبي وآخرون، 2018) إلى أن تقويم التحصيل الدراسي هدفه التمييز بين مستويات أداء الطلاب وأداء النظام المدرسي، وبالتالي

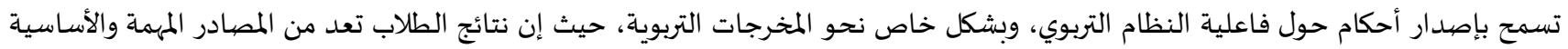

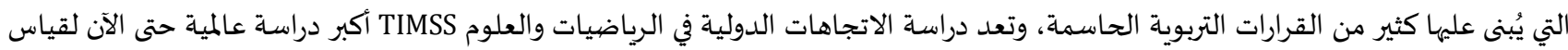

تحصيل الطلاب في الرياضيات والعلوم، وتُشرف على هذه الدراسة الرابطة الدولية لتقييم التحصيل التربوي (IEA).

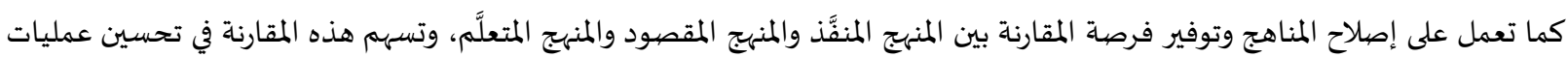
التعليم والتعلُّم على مستوى الأقطار المشارِكة. (Mullis et al.,2012)

إذ بدأت في عام 1995م بمشاركة ما يقارب من أربعين دولة من دول العالم، وتعقد مرة كل أربع سنوات، ومن الدول التي شاركت في الانطلاقة

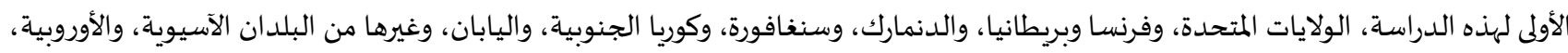

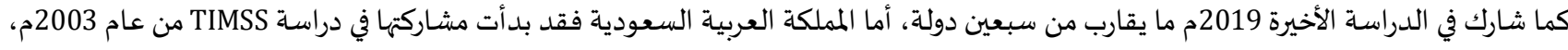

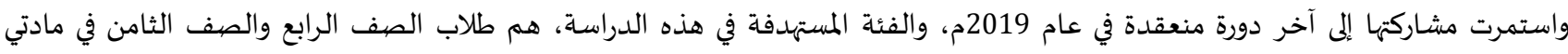

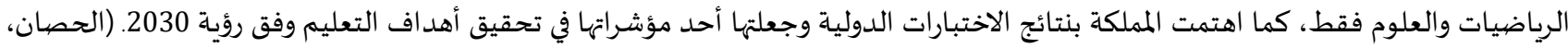

$(2015$

وقد ذكر (الشمراني وآخرون، 2016) أن نظام التعليم بالمملكة يواجه عدة تحديات، من أبرزها ضعف مخرجات التعليم العام، وهذا لا يرقى إلى مستوى الجهود التي تبذلها الدولة في مجال التعليم، كما أن التقارير الدولية كشفت عن قصور واضيح فاضح في مستوى الدول العبية المشاركة بشكل عام، ودول الخليج العربي بشكل خاص في العلوم والرياضيات تبدئ.

وحسب تقارير (Methods and Procedures in TIMSS) الصادرة من منظمة (IEA) في عام 2003م كان إجمالي الدول المُشاركة من مُختلف قارات العالم 46 دولة، وأظهرت ترتيب المملكة في أول مشاركة لها TIMSS2003، في المركز 45 بالرياضيات، أما في العلوم فقد حصلت على على المركز 41 في

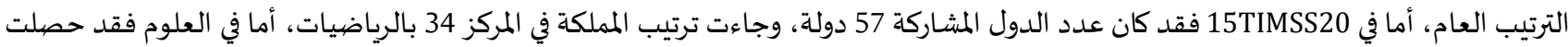

على المركز 32 بين الدول المشاركة. وهذا يشير إلى أن الأخطاء التي وقع بها الطلاب ناتجة عن مهارات فاقدة في المقررات الدراسية أو بسبب قصور في طرائق التدريس التي يستخدمها

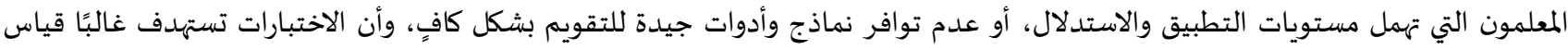
الأهداف التعليمية المعرفية في مستوياتها الدنيا، ولا سيما التذكر أو المعرفة، دون المستويات العليا من التفكير للأهداف المعرفية. (التركي وآخرون،

(2015

لذلك سعت وزارة التعليم حسب التقرير الصادر عام 2018م من هيئة تقويم التعليم والتدريب إلى وضيع الإطار الوطني لمعايير مناهج التعليم

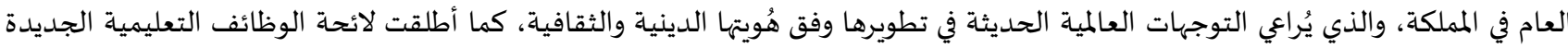

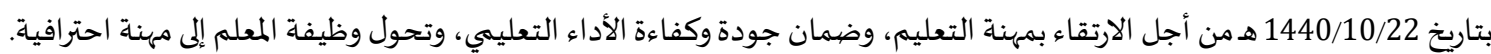

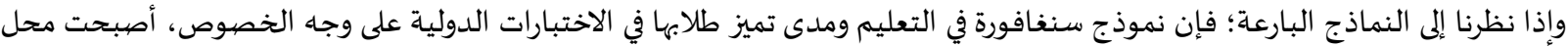

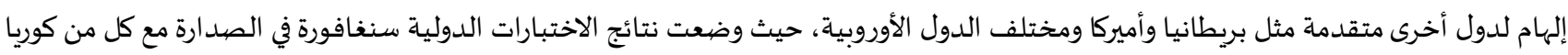

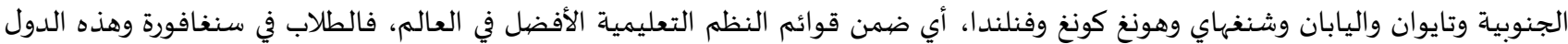

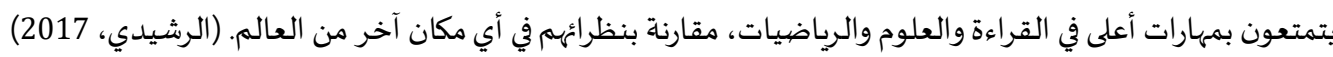

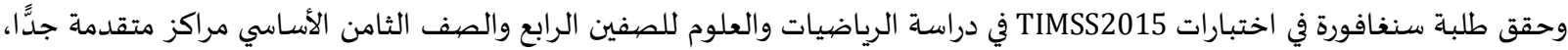

حيث جاء طلاب سنغافورة في المركز الأول عالميَّا بـ 611 نقطة في مادة الرياضيات، وبـ 618 نقطة في مادة العلوم (IEA,2015). كما حققت كوريا الجنوبية المركز الأول كأفضل نظام تربوي وتعليمي في العالم، فبعد أن كانت نسبة الأمية بين سكان كوريا، حين رحاء رحل الئ اليابانيون عنها 78\%، بذل الكوريون جهودًا جبارة للقيام بقفزة البد اية في نظامهم التعليمي، وأصبحت كوريا تتميز بأعلى معدل للالتحاق الإجمالي بالتعليم العالي

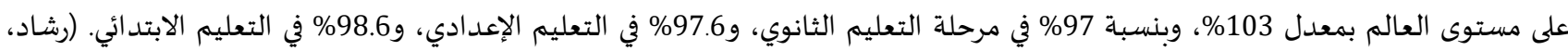

(2014

وحقق طلبة كوريا الجنوبية في اختبارات TIMSS2015 في دراسة الرياضيات والعلوم للصفين الرابع والصف الثامن الأسـاسي مراكز متقدمة جدًّا، حيث جاء طلاب كوريا في المركز الثالث عالميًّا بـ 606 نقطة في مادة الرياضيات، وبـ 613 نقطة في مادة العلوم (IEA,2015). 


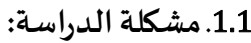

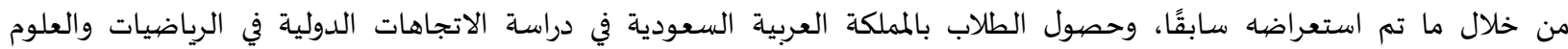
(TIMSS2015)

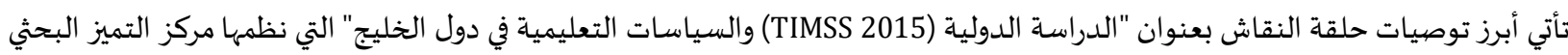

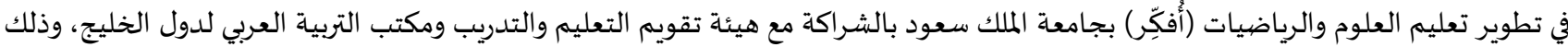

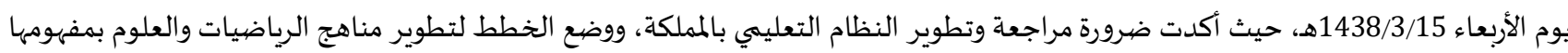

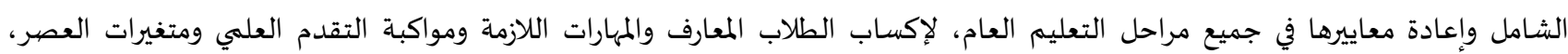
والاستفادة من تجارب الدول المتقدمة في نظمها التعليمية المتميزة. ولكي تستطيع المملكة العربية السعودية كإحدى الدول النامية اللحاق بركب الدول المتقدمة مثل سنغافورة والصين وكوريا الجنوبية واليابان، لإنانيا

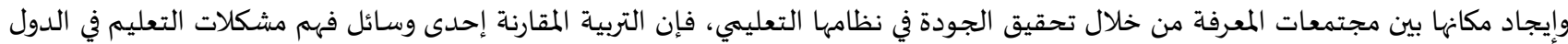

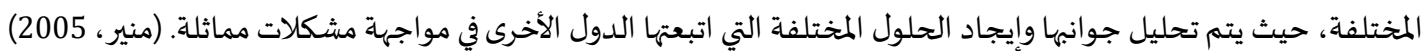

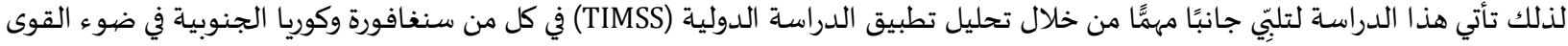

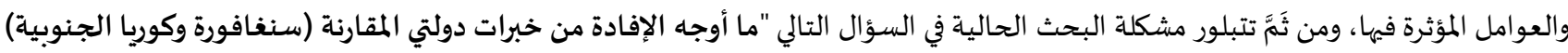

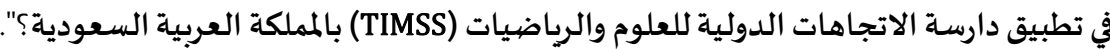

2.1 2.1 أسئلة الدراسة:

سعت الدراسة للإجابة عن التساؤلات التالية:

1. ما الأطر النظرية لدارسة الاتجاهات الدولية للعلوم والرياضيات (TIMSS) في الأدبيات التربوية المعاصرة؟ 2. ما واقع تطبيق دارسة الاتجاهات الدولية للعلوم والرياضيات (TIMSS) للصفين الرابع والثامن من التعليم الأسـاسي في كل من سنغافورة وكوريا

الجنوبية؛

3. ما القوى والعوامل المؤثرة التي أثَّرت في تطبيق الدراسة الدولية (TIMSS) في كل من سنغافورة وكوريا الجنوبية؟

4. ما أوجاه التشاباه والاختلاف في تطبيق الدراسة الدولية (TIMSS) بين كل من سنغافورة وكوريا الجنوبية؟

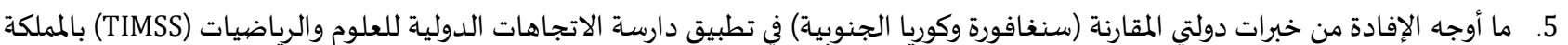

العربية السعودية؟

3.1

1. التعرُّف على الأطر النظرية لدارسة الاتجاهات الدولية للعلوم والرياضيات (TIMSS) في الأدبيات التربوية المعاصرة. 2. الكشف عن واقع تطبيق دارسة الاتجاهات الدولية للعلوم والرياضيات (TIMSS) للصفين الرابع والثامن من التعليم الأسـاسي في كل من سنغافورة وكوريا الجنوبية. 3. استعراض القوى والعوامل المؤثرة التي أثَّرت في تطبيق الدراسـة الدولية (TIMSS) في كل من سنغافورة وكوريا الجنوبية. 4. الوضيح أوجاه التشاباه والاختلاف في تطبيق الدراسـة الدولية (TIMSS) بين كل من سنغافورة وكوريا الجنوبية. 5. الإفادة من خبرات دولتي المقارنة (سنغافورة وكوريا الجنوبية) في تطبيق دارسة الاتجاهات الدولية للعلوم والرياضيات (TIMSS) بالمملكة العربية السعودياة.

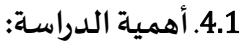

الأهمية النظرية:

1. تُسسهم الدراسة في الإضـافة العلمية للمكتبة التربوية، حيث إن دراسات المقارنة بين الدول التي تميَّزت في تطبيق الدراسة الدولية TIMSS قليلة. 2. تساهم هذه الدراسة في التعرف على التوجهات الحديثة والمعاصرة في تطبيق مناهج الرياضيات والعلوم في دولتي سنغافورة وكوريا مما يساهم في

تطويرها بالمملكة العربية السعودية. 3. جاءة الدراسـة الحالية استجابة لتوصيات الدراسـات (الشمراني وآخرون، 2016)، و(الزعبي وآخرون، 2018)، و(غريب، 2019) للكشف عن فئه القصور الواضح في مستوى مشاركة المملكة في الاختبارات الدولية للعلوم والرياضيات التي جعلت نتائجها أحد المؤشرات في تحقيق أهداف وهرون التعليم وفق رؤية 2030.

الأهمية التطبيقية:

1. يُفيد أصحاب القرار في مراجعة وتطوير النظام التعليمي بالمملكة، والاستفادة من تجارب الدول المتقدمة في نظمها التعليمية المتميزة. 
2. يدعم القائمين على التعليم في وضع الخطط لتطوير مناهج الرياضيات والعلوم بمفهومها الشامل وإعادة معاييرها في جميع مراحل التعليم العام، لإكساب الطلاب المعارف والمهارات اللازمة ومواكبة التقدم العلمي ومتغيرات العصبر.

3. يُفيد أصحاب القرار في وضيع معايير وضوابط للوسائل المتنوعة لتقويم الطلاب وفق جداول المواصفات والمعايير الدولية، وقياس المهارات العليا لديهم.

5.1

الحدود الموضوعية: اقتصر موضوع الدراسة الحالية على تناول الإطار النظري لدراسة TIMSS من حيث مفهومها وأهدافها ومراحلها وأبعادها وأدواتها ومستويات الأداء فهيها وأهميتها، ومقارنة تطبيق الاختبارات الدولية TIMSS في كل من سنغافورة وكوريا الجنوبية في ضوء القواء القوى والعوامل المؤثرة السياسية والجغرافية والسكانية والثقافية والاقتصادية، وواقع تطبيقها في دولتي المقارنة من حيث أهداف التعليم، ومنهج الرياضيات

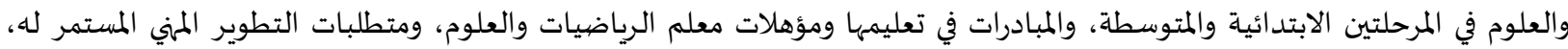
واستخدام التكنولوجيا، وتقييم الطلاب، وتأثير دراسة TIMSS على تعليم الرياضيات والعلوم لدى دولتي المقارنة، والإفادة من خبرات دولتي المقارنة بالمملكة العربية السعودية. الحدود المكانية: تتخذ الدراسـة من دولتي سنغافورة وكوريا كدول للمقارنة للاستفادة من تطبيقها في الاختبارات الدولية TIMSS، في كل منهما باعتبارهما دولتين رائدتين في التعليم. الحدود الزمانية: الفصل الدراسي الأول للعام الجامعي 1441هـ/2020م.

6.1 مصططحات الدراسـة:

:TIMSS •

دراسة TIMSS وهو اختصار لـTrends of the International Mathematics and Science Studies، وتعني الاتجاهات العالمية في التحصيل الدراسي للرياضيات والعلوم، وهو أحد الاختبارات والدراسات الدولية التي يتولى المركز الوطني للقياس والتقويم تطبيقها في المملكة العربية السعودية، بالتعاون مع المنظمات الدولية المشرفة على تلك الاختبارات في 70 دولة، بهدف قيداس الاتسات الاتجاهات في تحصيل الطلبة لمادتي الرياضيات والعلوم وتستهدف الصف الرابع والصف الثامن، لدراسـة أوجه الاختلاف والتباين بين النظم التربوية في تلك الدول، وذلك من أجل تحسين عملية التعليم والتعلُّم في التهات

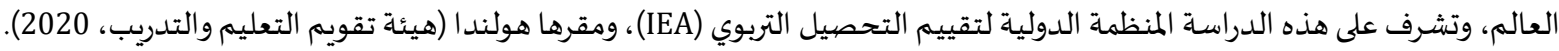
وتتبنَّ الباحثة تعريف مصطلح الدراسة الدولية TIMSS، كونه تعريفًا متفق عليه من هيئة تقويم التعليم والتدريب بالمملكة، ويوضح الهدف الإجرائي من هذه الدراسـة.

7.1. منهج الدراسة وخطواتها:

اعتمدت الدراسة الحالية على المنهج المقارن باعتباره أنسب المنهجيات لإصلاح وتطوير السياسات والنظم التعليمية، وذلك باستخدام أسلوب

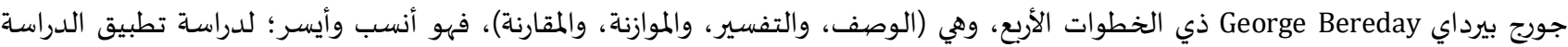
الدولية TIMSS في كل من سنغافورة وكوريا الجنوبية في ضيوء القوى والعوامل المؤثرة فهيا على النحو التالي (Holdrege et al, 2018): الوصف: وصف واقع تطبيق الدراسة الدولية TIMSS في كل من سنغافورة وكوريا الجنوبية، من حيث أهداف التعليم ومنهج الرياضيات والعلوم في المرحلتين الابتدائية والمتوسطة، والمبادرات في تعليم الرياضيات والعلوم، ومؤهلات المعلم ومتطلبات تطويره المهني المستمر، واستخدام التكنولوجيا، وتقييم الطلاب، وتأثير الدراسة الدولية اهند

التحليل أو التفسير: تفسير تطبيق الدراسة الدولية TIMSS في كل من سنغافورة وكوريا الجنوبية، في ضوء القوى والعوامل المؤثرة السياسية والجغرافية والسكانية والثقافية والاقتصادية. • المقابلة أو الموازنة والمناظرة: تحديد أوجاه التشاباه والاختلاف بين كل من سنغافورة وكوريا الجنوبية، من حيث القوى والعوامل السياسية والجغرافية والسكانية والثقافية والاقتصادية، وواقع تطبيق الدراسة الدولية TIMSS بين الدولتين. • المقارنة: استخلاص أوجاه الإفادة من خبرات دولتي المقارنة (سنغافورة وكوريا الجنوبية) في تطبيق دارسة الاتجاهات الدولية للعلوم والرياضيات بالمملكة العربية السعودية. وبالرجوع للمصادر والمراجع التي بيَّت مفهوم الدراسـة الدولية TIMSS وأهدافها ومراحلها وأبعادها وأدواتها ومستويات الأداء فيها وأهميتها، للإجابة عن السؤال الأول الذي ينص على: "ما الأطر النظرية لدارسة الاتجاهات الدولية للعلوم والرياضيات (TIMSS) في الأدبيات التربوية 
TIMSS: 1.2 أهداف دراسـة الاتجاهات الدولية للرياضيات والعلوم الهدف الأسـاسي من دراسة الاتجاهات الدولية للرياضيات والعلوم TIMSS يمثل معرفة ومقارنة مستوى أداء تحصيل طلاب الدول المشارِكة بمستوى أداء طلاب دول العالم بغرض تطوير مستوى التعليم والارتقاء باء إلى مستوى الجودة العالمية (الحميدي، 1431هـ). ويهدف مشروع (TIMSS) إلى تحقيق عدة أهد اف رئيسية، وتتمثل في (الغريب، 2012) و(الفهيدي، 1432هـ): التعرف على فرص التعليم المتاحة من قبل الدول المشاركة. التعرف على مدى استخد ام التكنولوجيا للأغراض العلمياة. وصف ومراقبة الإنجاز في مواد العلوم والرياضيات للصفين الرابع والثامن الأساسي. مساعدة دول العالم على تحسين جودة تعليم العلوم والرياضيات باعتبارهما مفتاح التقدم العلمي لأي دولة. تقديم معلومات مفصلة عن مناهج العلوم والرياضيات في كل دولة مشاركة ودراساة فاعليتهما وطرق تدريسهما والتطبيق العملي لهما. إعطاء صورة واضحة وديناميكية للتغيُرات في تطبيق السياسات والممارسات التربوية للدول المشـاركة والتطورات الجديدة في تعليم العلوم والرياضيات حول العالم. توفير بيانات مرجعية تساعد في إجراء تحليلات متقدمة تمكن تزويد صانعي السياسات التربوية بمؤشرات تسهم في تحسين نوعية تعليم وتعلم العلوم والرياضيات.

2.2. مراحل دراسـة الاتجاهات الدولية للرياضيات والعلوم: TIMSS مرت هذه الدراسة بالمراحل التالية (Martin, \& Mullis, 2019): المرحلة الأولى: الدراسة العالمية الأولى للرياضيات 1964م: بدأت هذه الدراسة عام 1964م، لكنها كانت تحتوي على الرياضيات فقط، وتعتبر هي الدراسة العالمية الأولى للرياضيات، وقد شاركت بها أكثر من (12) دولة. المرحلة الثانية: الدراسة العالمية الثانية للرياضياتيات 1980م: أجريت هذه الدراسة في عام (1980م-1981م)، وقد شـارك فيها أكثر من (20) دولة، وهي أيضًا احتوت على مادة الرياضيات فقط. المرحلة الثالثة: الدراسـة العالمية الثالثة للرياضيات والعلوم 1990م: بدأت هذه الدراسة عندما تم وضيع مادة العلوم في خطة هذا المشروع، وذلك في عام 1983م؛ وفي عام 1990م قامت منظمة (IEA) بعقد اجتماع عام شامل يهدف إلى وضع العلوم والرياضيات معًا ضمن منهج أو خطة هذه الدراسـة في نظام أسـاسي يبنى كل أربع سنوات، ويعتبر هذا القرار بمثابة أول خطوة حقيقية تهتم بتشخيص اتجاهات وميول التلاميذ نحو مادتي العلوم والرياضيات وقياسها بمقياس عالمي دولي، والذي يعتبر المقياس الأكبر للدراسات الدولية المقارنة، وأشرفت على الدراسة الرابطة الدولية لتقييم التحصيل التربوي (IEA). المرحلة الر ابعة: الدراسة الدولية الثالثة للرياضيات والعلوم 1999م: أعيد تطبيق الدراسة الدولية الثالثة للرياضيات والعلوم في عام 1999م نتيجة لما أحدثته الدراسـة الثالثة للرياضيات والعلوم عام (1995م) من أثر كبير في كثير من البلدان المشاركة؛ ترجمت في بعضها إلى خطط في

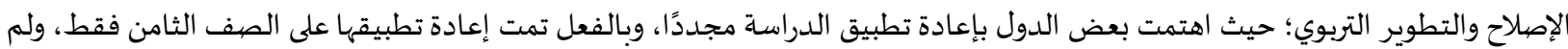
تتم على الصف الرابع. المرحلة الخامسة: مشروع الدراسة الدولية للاتجاهات في العلوم والرياضيات 2003م: هدف مشروع الـ(TIMSS) في عام 2003م إلى تقييم تحصيل الطلاب في عمر 9 سنوات (في الصف الرابع)، والطلاب في عمر 13 سنة (في الصف الثامن)، حسب نظام تقسيم المراحل التعليمية وتوزيع الطلاب بها حسب أعمارهم في كل دولة مشاركة، وذلك في مادتي العلوم والرياضيات، وقد تضاعف عدد الدول العربية المُشاركة، ليصل إلى عشر

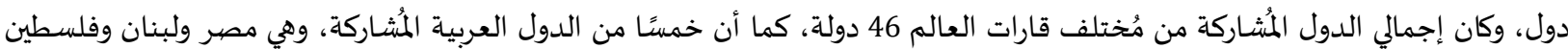

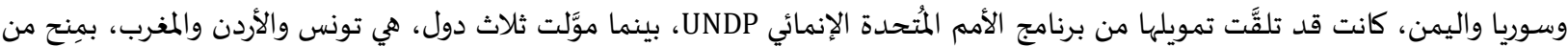

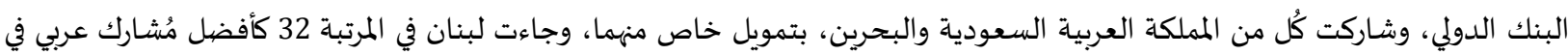

الرياضيات، بمجموع نقاط 433 نقطة. المرحلة السـادسة: مشروع الدراسة الدولية للاتجاهات في العلوم والرياضيات 2007م: إن مشروع الا(TIMSS 2007) ارتفع فياه عدد الدول

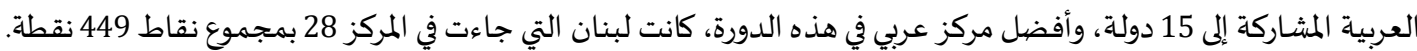
المرحلة السـابعة: مشروع الدراسـة الدولية للاتجاهات في العلوم والرياضيات 2011م: وقد شاركت فياء 60 دولة من قارات العالم، وفي المُجمَل كان التمثيل العربي ونتائجها أفضل من الدورات السابقة. 
• المرحلة الثامنة: مشروع الدراسة الدولية للاتجاهات في العلوم والرياضيات 2015: في دورة 2015م، شاركت فيها 64 دولة من دول العالم،

وكانت دولة الإمارات العربية المتحدة أفضل دولة عربية مُشُشاركة.

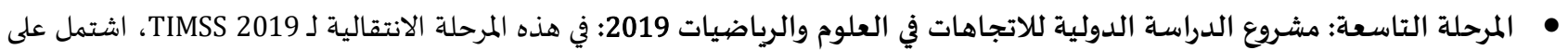

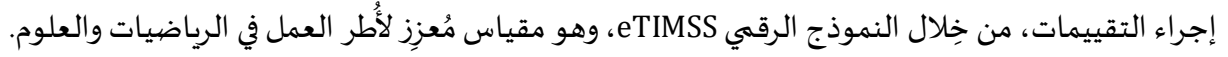

3.2. أبعاد الدراسـة الدولية للاتجاهات في العلوم والرياضيات TIMSS:

تشتمل على بعدين لكل من مادتي العلوم والرياضيات، هما: (الشمراني وآخرون، 2016)

• بعد المحتوى: ويشتمل على مجالات المحتوى الرئيسية للعلوم، وكذلك للرياضيات التي يتناولها الاختبار في الصفوف المستهدفة، وهما الصفان

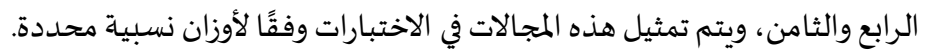

• بعد التفكير: ويشتمل على مستويات التفكير المتوقع ممارستها من قبل الطلاب، عند دراسة محتوى العلوم والرياضيات في الصفين المحددين،

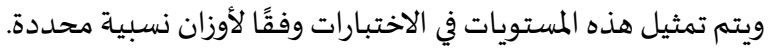

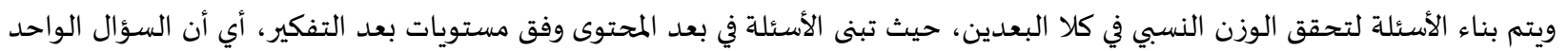

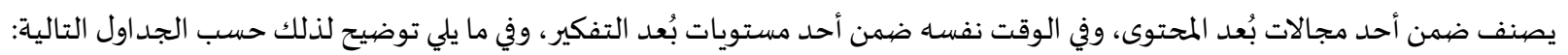
أولًا: الرياضيات:

جدول (1): مجالات المحتوى التي يتناولها اختباردراسة TIMSS في الرياضيات

\begin{tabular}{|c|c|}
\hline \multicolumn{2}{|c|}{ الصف الثامن } \\
\hline الوذن النسبي & 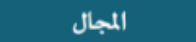 \\
\hline$\%$ r. & الأعداد \\
\hline$\pi r$. & الجبر \\
\hline$\%$ r. & الهندسة \\
\hline$\%$ r. & البيانات والاحتمالات \\
\hline$\%$. & المجهوع \\
\hline
\end{tabular}

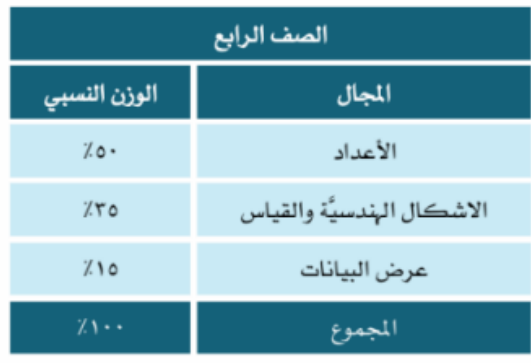

جدول (2): مستويات التفكير المتوقعة من الطلاب في أثناء دراسة الرياضيات التي حددتها دراسة TIMSS

\begin{tabular}{|c|c|}
\hline \multicolumn{2}{|c|}{ الصف الثامن } \\
\hline الوذن النسبي & المستوى \\
\hline$\%$ & المعرفة \\
\hline$\% \varepsilon$. & التطبيق \\
\hline$\%$ & الاستدلال \\
\hline$\% \ldots$ & المجموع \\
\hline
\end{tabular}

\begin{tabular}{|c|c|}
\hline \multicolumn{2}{|c|}{ الصف الرابع } \\
\hline الوزن النسبي & المستوى \\
\hline$\% \varepsilon$. & المعرفة \\
\hline$\% \varepsilon$. & التطبيق \\
\hline$\%$. & الاستدلال \\
\hline$\%$ & المجموع \\
\hline
\end{tabular}

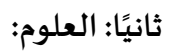
جدول (3): مجالات المحتوى التي يتناولها اختباردراسة TIMSS في العلوم

\begin{tabular}{|c|c|}
\hline \multicolumn{2}{|c|}{ الصف الثامن } \\
\hline الوزن النسبي & المجال \\
\hline tro & الأحياء \\
\hline zr. & الكيمياء. \\
\hline tro & الفيزياء \\
\hline$z r$. & علم الأرض \\
\hline$\%$ & المجموع \\
\hline
\end{tabular}

\begin{tabular}{|c|c|}
\hline \multicolumn{2}{|c|}{ الصف الرابع } \\
\hline الوزن النسبي & المجال \\
\hline$\%$ \&o & علم الحياة \\
\hline tro & علم الفيزياء \\
\hline \%r. & علم الأرض \\
\hline$\%$. & المجهوع \\
\hline
\end{tabular}


جدول (4): مستويات التفكير المتوقعة من الطلاب في أثناء دراسة الرياضيات التي حددتها دراسة TIMSS

\begin{tabular}{|c|c|}
\hline \multicolumn{2}{|c|}{ الصف الثامن } \\
\hline الوزن النسبي & المستوى ل المع \\
\hline /ro & المعرفة \\
\hline \%ro & التطبيق \\
\hline$\% r$. & الاستدلال \\
\hline$\%$ & المجهموع \\
\hline
\end{tabular}

\begin{tabular}{|c|c|}
\hline \multicolumn{2}{|c|}{ الصف الرابع } \\
\hline الوزن النسبي & المستوى \\
\hline$\%$. & المعرفة \\
\hline$\%$. & التطبيق \\
\hline$\% r$. & الاستدلال \\
\hline$\%$. & المجهوع \\
\hline
\end{tabular}

4.2. أدوات دراسة الاتجاهات الدولية للعلوم والرياضيات TIMSS:

تعتمد دراسة الاتجاهات الدولية للعلوم والرياضيات TIMSS على مجموعة من الأدوات تم تطويرها من قبل مجموعة من خبراء التربية لجمع

البيانات الضرورية لتحقيق أهداف الدراسـة، وهي كالتالي: (الشمراني وآخرون، 2016) 1 1 الاستبانات، وتنقسم إلى:

استبانة الطالب: يقوم كل طالب مشارك في TIMSS بتعبئة استبانة تشمل عدة جوانب تتعلق بالبيئة المنزلية، والمناخ المدرسي للتعلم، والاتجاهات نحو العلوم والرياضيات.

استبانة المعلم: يقوم المعلمون المشاركون في TIMSS بتعبئة استبانة تتضمن الخلفية الأكاديمية والمؤهلات العلمياة، الرضا الوظيفي، طريقة التعليم، استخدام الحاسوب.

استبانة المدرسة: يطلب من كل مدير مدرسة مشاركة في TIMSS تعبئة استبانة تتضمن تنظيم المدرسة، وأهدافها، وأدوار مدير المدرسة،

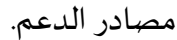
استبانة المنهاج: يتولى المنسق الوطني في كل دولة من الدول المشاركة بتعبئة الاستبانة، وتشمل بنية المنهج، تسلسل محتوى المنهج، وتنظيم المنهج، ومراقبة وتقييم المنهج المطبق والوسائل التعليمية. كتيبات الاختبار:

تحتوى كتيبات الاختبار على أسئلة في العلوم والرياضيات، بعضها من نوع الاختيار المتعدد، وبعضها من نوع الاستجابات الحرة التي تستدعي

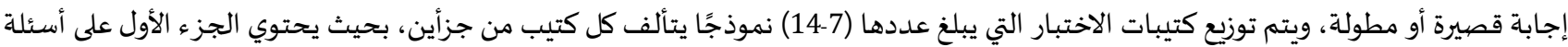

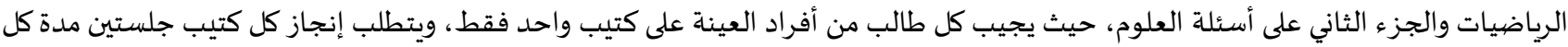

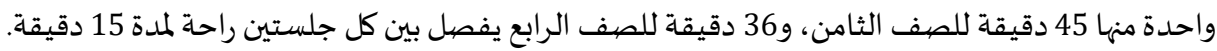

5.2. مستويات الأداء في دراسة الاتجاهات الدولية في الرياضيات والعلوم TIMSS: حدَّدت مستويات الأداء في دراسة الاتجاهات الدولية في الرياضيات والاتهاتوات العلوم TIMSS إلى أربعة مستويات للأداء يمكن تصنيف أداء أداء الطلاب بناء عليها، بحيث يُمكَّن كل بلد مشـارك من التركيز على رفع نسبة الطلاب إلى المستويات العليا من الأداء، وهذه المستويات هي: (Ina et al., 2011)

$$
\begin{aligned}
& \text { مستوى الأداء المتقدم في التحصيل عند } 625 \text { نقطة فما فوق. } \\
& \text { • مستوى الأداء العالي في التحصيل عند } 550 \text { نقطة وأعلى. } \\
& \text { • مستوى الأداء المتوسط في التحصيل عند } 475 \text { نقطة وأعلى. } \\
& \text { • مستوى الأداء المنخفض في التحصيل عند } 400 \text { نقطة وأعلى. }
\end{aligned}
$$

6.2. أهمية دراسة الاتجاهات الدولية في الرياضيات والعلوم TIMSS: يوضح (الدهمان، 2014) و(سعيد، 2011) أن أهمية دراسة الاتجاهات الدولية في الرياضيات والعلوم يمكن توضيحها كالتالي: الحصول على بيانات شاملة حول المفاهيم والمواقف التي تعلمها الطلاب في مادتي الرياضيات والعلوم للصفين الرابع والثامن. القدرة على قياس مدى التقدم في تعليم وتعلم الرياضيات والعلوم بالمقارنة مع الدول الأخرى في الوقت نفسـه. الوصهول إلى أهم وأفضل الوسـائل المؤدية إلى تعليم أفضل، وذلك عبر مقارنة نتائج الاختبارات لدى أي دولة مشاركة مع نتائج الدول الأخرى في سياق السياسات والنظم التعليمية المطبقة. قياس مدى فاعلية تعليم الرياضيات والعلوم في مدارس الدول المشاركة بهدف مساعدة هذه الدول على إجراء الإصلاحات التربوية اللازمة والمبنية على التقييم الموضوعي الشمولي. تطوير تعليم وتعلم الرياضيات والعلوم في رحلة ما قبل التعليم الجامعي في جميع أنحاء العالم. 
تعتبر دراسة TIMSS مصدر معلومات يساعد المسؤولين على اتخاذ القرارات السليمة نحو العملية التربوية لديهم.

يعطي مؤشرات مقارنة داخل النظام التربوي الواحد، بما يمكن من تجديد بوصلة التطور في النظام التعليهي وبالتالي تجويد المخرجات. ومن خلال ما سبق ترى الباحثة أن الدراسة الدولية TIMSS توفر للدول المشاركة قاعدة بيانات نوعية وشاملة عن كل المراحل التي تتم فيها

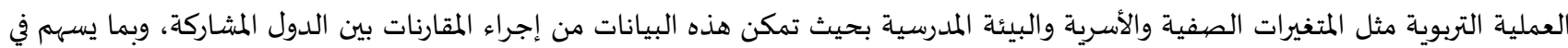

تطوير الأنظمة التربوية وتحسين نوعية التعليم والتعلم، وكذلك إعادة النظر في المناهج بما يتوافق مع المناهج في الدول المتقدماتهية

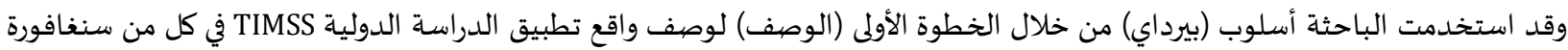
وكوريا الجنوبية، من حيث أهداف التعليم ومنهج الرياضيات والعلوم في المرحلتين الابتدائية والمتوسطة، والمبادرات في تعليم الرياضيات والعلوم،

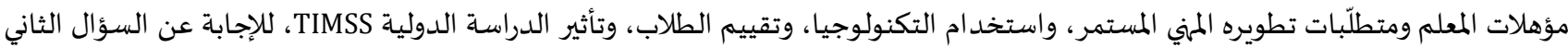
الذي ينص على: "ما و اقع تطبيق دارسة الاتجاهات الدولية للعلوم والرياضيات (TIMSS) للصفين الر ابع والثامن من التعليم الأسـاسي في كل من

سنغافورة وكوريا الجنوبية؟".

7.2. و اقع تطبيق دارسـة الاتجاهات الدولية للعلوم والرياضيات (TIMSS) للصفين الر ابع والثامن من التعليم الأسـاسي في سنغافورة:

1.7.2. أهداف التعليم في دولة سنغافورة:

يعتبر نظام التعليم في سنغافورة من أفضل أنظمة التعليم في العالم، كما تعدُّ التجربة السنغافورية في التعليم من التجارب الرائدة، حيث تسعى وزارة التعليم إلى مسـاعدة الطلاب على اكتشـاف مواهبهم، واستغلال طاقاتهم بأفضل شكل ممكن، وتحقيق نتائج جيدة، كما خصَّصت الحكومة للتعليم خُمس ميزانية الدولة، وخلال السنوات الأخيرة، عملت سنغافورة على جعل نظامها التعليمي أكثر مرونة واستجابة لاختيارات الطلاب، حيث يتمثل الهدف من ذلك في منحهم اختيارات أوسع تتلاءم مع كفاءاتهم وطاقاتهم، فعندما يكونون قادرين على اختيار ماذا وكيف يتعلمون، فإنهم يستطيعون

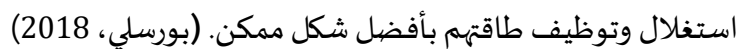

ومن أبرزأهداف التعليم في دولة سنغافورة ما يلي: (الشربيني، 2018)، (Tan, 2008):

تجديد برامج التعليم المهن، إضافة إلى إعادة هيكلة المناهج الدراسية، ومسارات الدخول إلى المدارس المهنية. تشجيع الطلبة للتعرف إلى مواهبهم وكفاءتهم في مرحلة مبكرة، ومتابعة تعليمهم الذي يُركِّز على المهنة طوال مراحل الدراسة الابتدائية والإعدادية إدية والثانوية، ومع انتشار التكنولوجيا، بدأت الوزارة تستخدمها في الصفوف الدراسية للابتعاد عن نمط التعلم التقليدي. مساعدة الطلاب على تنمية شغفهم وتطوير قدراتهم وكفاءاتهم وشخصيتهم وقيمهم، كي يساهموا في تقدم سنغافورة. تكوين القوى العاملة المدربة والمؤهلة أكاديميًّا، وتمكين الشباب من الالتحاق بسوق العمل. إعد اد مواطنين صيالحين مُدركين لمسؤولياتهم تجاه الأسرة والمجتمع والوطن، وغرس الأخلاق والقيم التي ينادي بها المجتمع. العمل على التماسك الاجتماعي والوحدة الوطنية من خلال التعليم.

2.7.2. منهج الرياضيات في المرحلتين الابتدائية والمتوسطة في سنغافورة: يؤكد إطار منهج الرياضيات في سنغافورة في جميع المستويات من التعليم الابتدائي إلى التعليم ما قبل الجامعي، على تطوير قدرات الطلاب

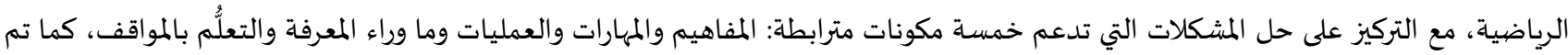
تصميم منهج الرياضيات بطريقة لولبية في مفاهيم (الأرقام والجبر والهندسة والقياس) ويعرض الشكل التوضيحي أدناه (شكل1) ملخصيًا للمفاهيم

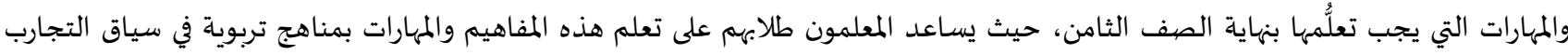

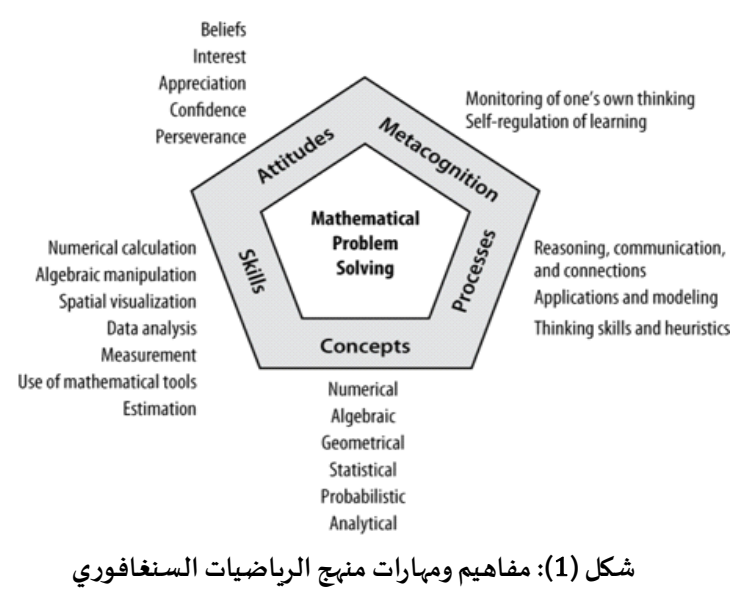


3.7.2. منهج العلوم في المرحلتين الابتدائية والمتوسطة في سنغافورة: يؤكد إطار منهج العلوم في سنغافورة على ثلاثة مجالات أساسية: المفاهيم في مستوى المعرفة والفهم والتطبيق؛ والمهارات والعمليات؛ والأخلاق والتعلم بالمواقف، في موضوعات (المادة والطاقة والحياة والأرض والتفاعلات)، ويؤكد ممارسة البحث العلمي، كما يعتمد المعلمون طريقة الاستكشاف في تدريس الطلاب التي تربطهم بحياتهم اليومية والظواهر البيئية، ويعرض الشكل التوضيحي أدناه (شكل 2) ملخصيًا للمفاهيم والمهارات التي يجب واهب تعلمها بنهاية الصف الثامن. (الغامدي، 2018)

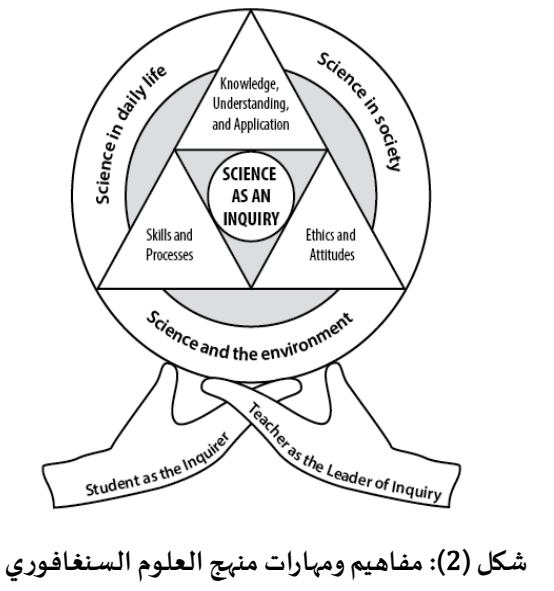

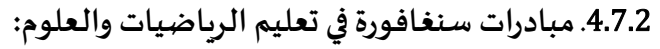
هناك برامج تم تطبيقها لإشراك الطلاب ذوي الاهتمامات المتنوعاة وتلبية احتياجاتهم، على سبيل المثال، قد يلتحق طلاب المدارس الثانوية الذين

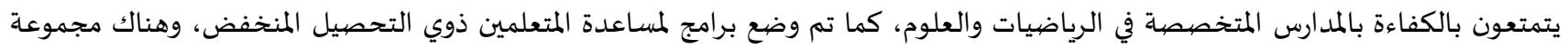

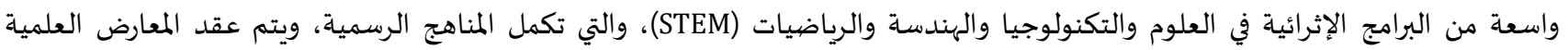

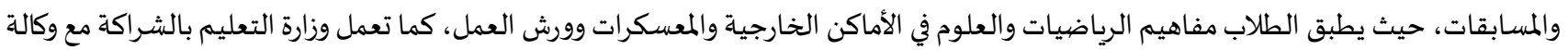
العلوم والتكنولوجيا ومركز العلوم لتصميم برامج للطلاب الذين لهم اهتمامات ومواهب محددة، وتوفر وزارة التعليم فرصيًا للطلاب المهتمين بالرياضيات والعلوم العميقين بالعمل في مشاريع بحثية مع مرشدين من معاهد التعليم العالي. (الشربيني، 2018).

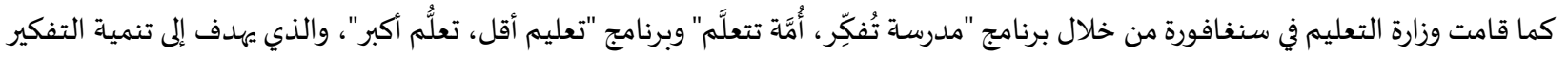

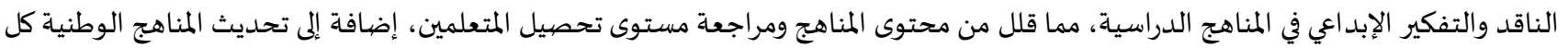
5 سنوات. (Tan,2016).

5.7.2. مؤهلات معلم الرياضيات والعلوم:

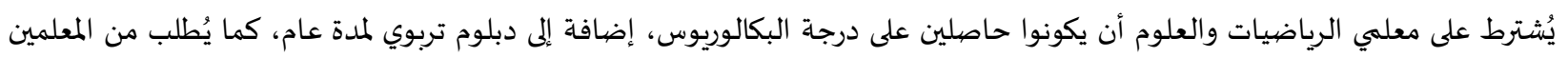
المتدربين إكمال تدريب تعليمي تربوي لمدة 10 أسابيع على الأقل، تحت إشراف معلمين ذوي الخبرة، بحيث يترجمون ما تعلَّموه نظريَّا بالممارسة دارئ داخل

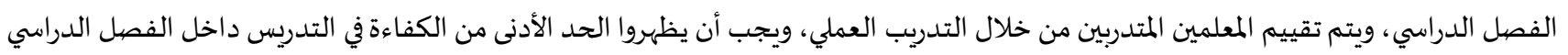
من أجل التخرج، وعند التخرج يتلقى المعلمون المستجدون مزيدًا من التوجياه، ويساعدهم على ذلك تخفيف نصابهم من جدول الحصص (20) ساعات تدريس أقل). (عيسان، 2009) وعند التخج 6.7.2. متطلبات التطوير المهني المستمر للمعلم: التدريب الأوَّلي للمعلمين المستجدين ليس سوى نقطة انطلاق، لذلك تعمل وزارة التعليم بشكل وثيق مع المعهد الوطني للتدريب لتقديم دورات

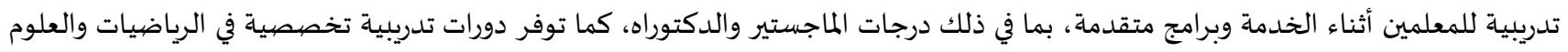

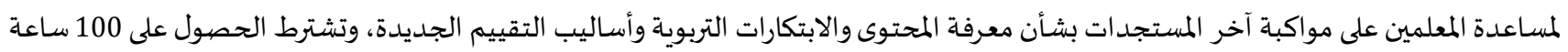

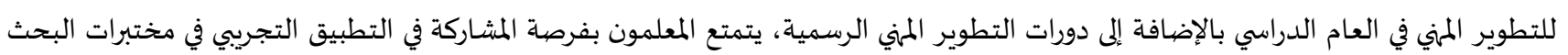
وفي قطاعي الأعمال والمجتمع لكي يكتسبوا خبرات جديدة تفيد طلابهم، كما تشجع وزارة التعليم على نمو ثقافة التميز المهني والابتكار، فكان إنشاء

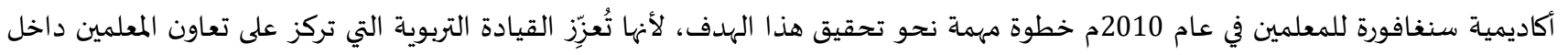
المدارس والمجتمعات المهنية، كما تهدف إلى تعزيز ثقافة التميز في التدريس. (شهاب، 
8.7.2. تعليم الرياضيات والعلوم في الصفوف الابتدائية والمتوسطة: يتم تعليم الطلاب من قبل معلمين متخصصين في الرياضيات والعلوم، وتتجهاه وزارة التعليم نحو مراجعة برامج التدريب قبل مباشرة المعلم

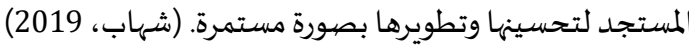

9.7.2 استخدام التكنولوجيا:

يوفر مخطط سنغافورة الرئيسي لتكنولوجيا المعلومات والاتصالات (ICT) في التعليم إرشادات حول استخدام تكنولوجيا المعلومات والاتصالات

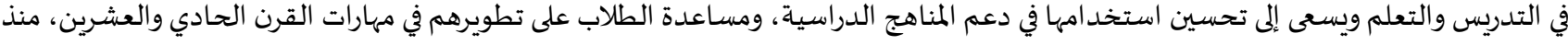
عام 2008م، كما تم إدخال الآلات الحاسبة في الصف الحائ الحس الابتدائي، لتعزيز عملية التدريس والتعلم، وللسماح للطلاب بالتركيز على حل المشكلات

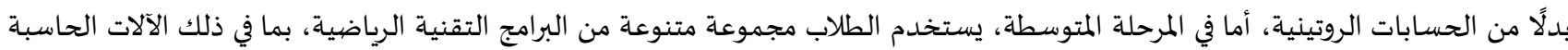

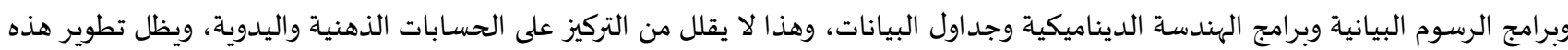
المهارات أولوية؛ يتوقع من الطلاب تطوير وتطبيق حس الأعداد ومهارات التقدير للتحقق من مدى معقولية الإجابات التي تم الحصول عليها باستخدام

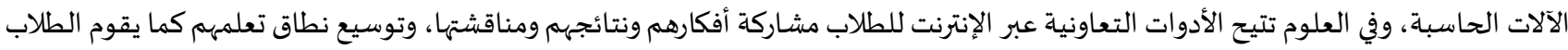
أيضًا باستكشاف وتصور المفاهيم المجردة باستخدام مقاطع الفيديو والرسوم المتحركة والمحاكاة لمعالجة المتغيرات وتحديد العلاقات بينها (رشاد،

10.7.2. تقييم الطلاب في الرياضيات والعلوم: تقوم المدارس بتقييم الطلاب بشكل رسمي وغير رسمي، حيث إنها تُجري عادةً ما لا يقل عن تقييمين نهائيين كل عام، كما يتبنى المعلمون مجموعة متنوعة من أساليب التقييم المناسبة، مثل العروض التقديمية الشفوية والاختبارات التحريرية على أن تتضمَّن المستويات العليا من التفكير، وتسمح التقييمات التكوينية للمعلمين بمراقبة تقدم الطلاب وتحديد نقاط القوة والضعف وتقديم ملاحظات مفيدة وفورية، كما أها تسمح للمعلمين بتكييف طرق التدريس والمواد مع احتياجات الطلاب وقدراتهم، وتزويد أولياء الأمور بانتظام بمستوى تحصيل الطلاب من خلال التقارير والمكالمات الهاتفية الشخصية واجتماعات الآباء والمعلمين التي تنظمها المدرسة، كما يتم إجراء الامتحانات الوطنية المتوافقة مع المناهج الدراسية الوطنية في السنة الأخيرة في كل من التعليم الابتد ائي والإعد ادي والثانوي، للتحقق من مدى إتقان الطلاب للمهارات وتحسين مخرجات التهات التعليم. (الرشيدي، 2017)

:TIMSS تأثير الدراسة الدولية: 11.7.2

تستخدم سنغافورة بيانات المشاركة في الدراسة الدولية TIMSS لتحديد نقاط القوة والضعف مثل الأخطاء الشائعة وصعوبات التعلم، ويتم مشاركة الرؤى مع رؤساء أقسام الرياضيات والعلوم، كما يعمل المعلمون معًا لابتكار طرق للتدريس والتعلم لمعالجة صعوبات تعلم الطلاب التي حددتها الدراسـ، كما تستخدم تلك البيانات لمراجعة السياسات التربوية والبرامج التعليمية.

8.2. و اقع تطبيق دارسة الاتجاهات الدولية للعلوم والرياضيات (TIMSS) للصفين الر ابع والثامن من التعليم الأسـاسي في كوريا الجنوبية:

1.8.2 أهداف التعليم في دولة كوريا الجنوبية:

واجهت كوريا الجنوبية تحديات هائلة من القرن العشرين، فقد خضع شعبها لسيطرة اليابان أكثر من خمس وثلاثين سنة، وقد كانت هناك صلة

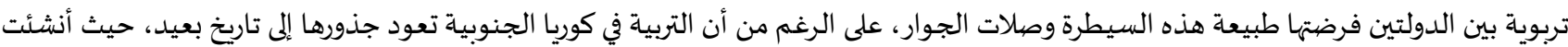
أول مدرسة نظامية فهها عام 372م، لكن الصياغة التعليمية والهيكل التنظيمي التربوي الحديث لم يصل بعد إلى الخمسين عامًا، ومع ذلك فثمار التربية

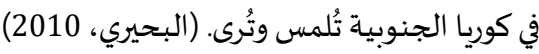

ومن أبرزأهداف التعليم في دولة كوريا الجنوبية ما يلي: (خليل، 2002) تحقيق المساواة في فرص التعليم واستمراريته.

يهتم بصورة فعالة بإكساب المهارات وتعزيز القدرات الأساسية، والتطوير النوعي للتربية العلمية. المشـاركة في عمليات التنمية من خلال بناء الإنسان الواعي المبدع والملتزم بالعمل والأخلاق. تعزيز مكانة التربية والتعليم، والاهتمام بالطلاب منذ مرحلة رياض الأطفال وبناء أجسامهم وتنمية لغتهم وذكائهم وغرس قيم التكيف الاجتماعي في نفوسهم وسلوكهم. بناء بيئة تعليمية صحية تُمكِّن من التعلم التعاوني والتعلُّم الذاتي مدى الحياة. ضمان حصيول جميع الطلاب على التعليم دون تمييز وفقًا لقدراتهم. 
2.8.2. منهج الرياضيات في المرحلتين الابتدائية والمتوسطة في كوريا الجنوبية:

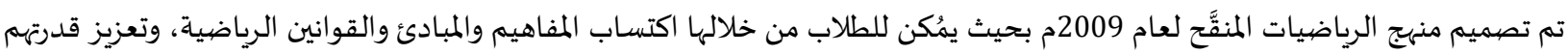

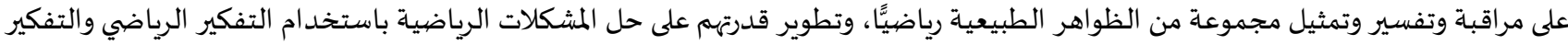

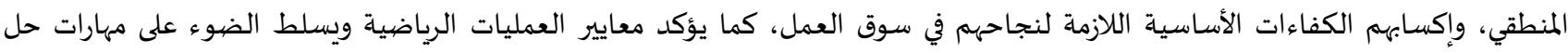
المشكلات الرياضية والتفكير الرياضي والتواصل الرياضي والاستدلال، وتنمية الشعور لديهم بالثقة والسلوك الإيجابي تجاه الرياضيات. (البحيري،

\subsection{2 منهج العلوم في المرحلتين الابتدائية والمتوسطة في كوريا الجنوبية:}

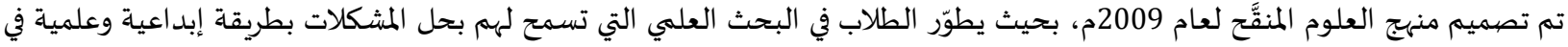
الحياة اليومية، كما يساعد الطلاب على فهم مفاهيم العلوم الأساسية من خلال الأنشطة الاستكشافية وتفسير الظواهر الطبيعية، ويؤكد أهمية

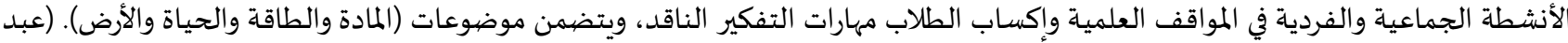

العاطي، 2009)

4.8.2 مبادرات كوريا الجنوبية في تعليم الرياضيات والعلوم:

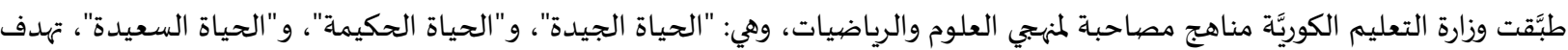

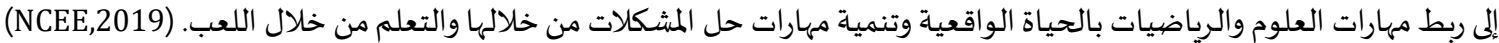

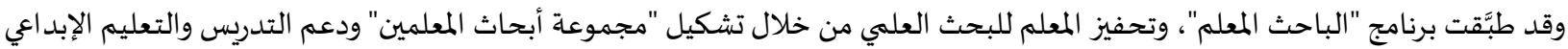
وتشجيع المعلمين لاستخدام المواد التعليمية التي طوروها بأنفسهم وتفعيلها في حصصيهم الدراسية، كما أن المناهج الوطنية يتم تحديثها كل 5 سنوات؛ وقد تم اعتماد أحدث مراجعة في عام 2015 (Mani,2018) وحدد تقرير صادر في عام 2015م عن Yong Zhao لمعهد ميتشل ومقره واشنطن أنه يمكن تعلُّم ستة دروس من أنظمة التعليم الناجحة في سنغافورة وكوريا الجنوبية وهونغ كونغ واليابان، وهذه الدروس الستانة هي:

$$
\begin{aligned}
& \text { • تجويد مخرجات التعليم. } \\
& \text { ت تحسين تكافؤ الفرص التعليمية. } \\
& \text { ه تحويل علم أصول التدريس من التنظير إلى التجريب. } \\
& \text { الاستفادة من التكنولوجيا. } \\
& \text { تطوير المناهج. }
\end{aligned}
$$

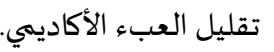

$$
\begin{aligned}
& \text { 5.8.2 مؤهلات معلم الرياضيات والعلوم: }
\end{aligned}
$$

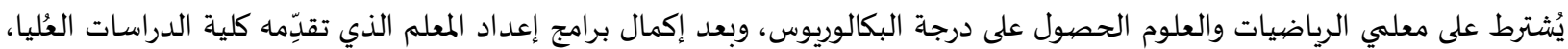

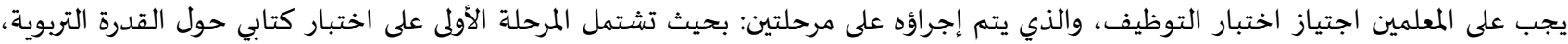

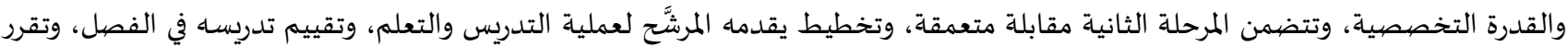

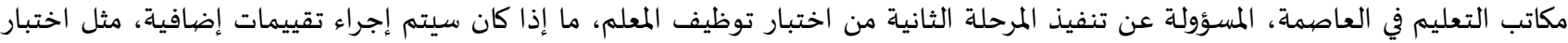

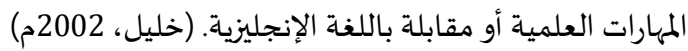

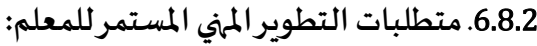

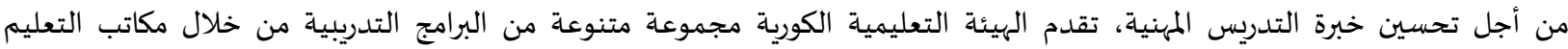

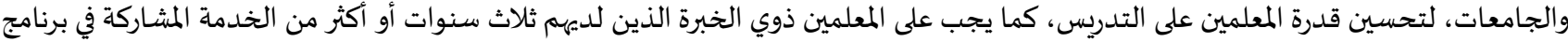

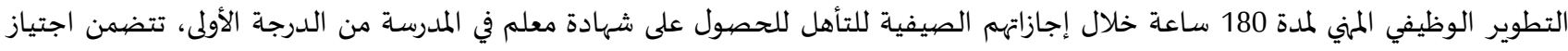
المهارات الأساسية (10\% إلى20\% من برامج التدرب)، وطرق التدريس العامة (10\% إلى20\%)، والتمكن العلمي للمادة (60\% إلى 80\%) 
7.8.2. تعليم الرياضيات والعلوم في الصفوف الابتدائية والمتوسطة: زمن الحصة 40 دقيقة في المدرسة الابتدائية، و45 دقيقة في المدرسة المتوسطة، و50 دقيقة في المدرسة الثانوية، ويتم تعليم الطلاب من قبل معلمين متخصصين في الرياضيات والعلوم، كما يتم تدريس طلاب المرحلة الابتدائية من قبل "معلمي الفصل"، أما طلاب المرحلة المتوسطة فيتم

تدريسهم من قبل "معلمي المادة". (Noh,2012)

8.8.2 استخدام التكنولوجيا:

يتعامل المنهج الوطني الكوري مع التعليم المدعوم بتكنولوجيا المعلومات والاتصالات، لذلك يوصى باستخدام الآلات الحاسبة وأجهزة الكمبيوتر

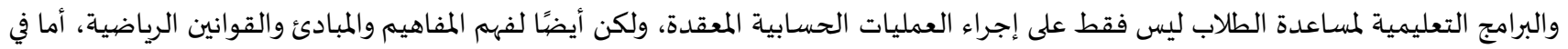
منهج العلوم فيُحدد الاستخدام المناسب لشبكات اتصال الإنترنت والوسائط المتعددة لحل الأنشطة العملية واستخدام المختبرات الحاسوبية

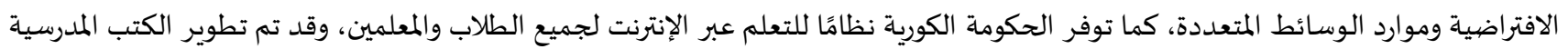
الرقمية للعلوم والرياضيات، علاوة على ذلك، بالنسبة للأسر الفقيرة والمدارس الريفية، حاولت الحكومة الكورية توفير أجهزة كمبيوتر شخصيية وخدمات الاتصال بالإنترنت والبنية التحتية للمعلومات، بما في ذلك زيادة الدعم المادي والمالي. (Guo,2015)

9.8.2 تقييم الطلاب في الرياضيات والعلوم: الطمات

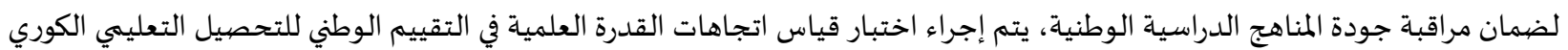

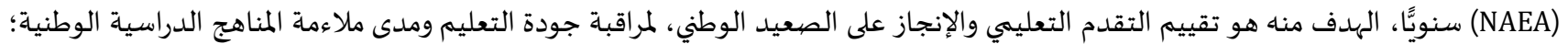

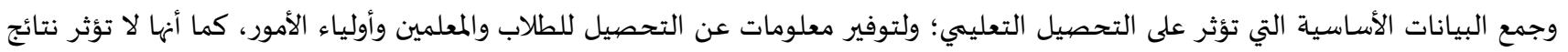
الطلاب في NAEA على درجاتهم المدرسية، وإنما تقدم المدارس الدعم المناسب للطلاب بناءً على النتائج الخاصية بهم، كما تُوفِّرِ للوزارة التعليمية الكورية

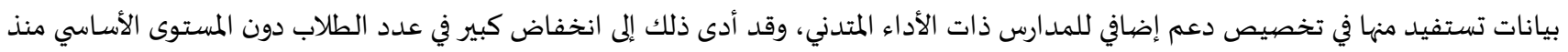
أن تم تطبيق NAEA لأول مرة في عام 2008م، كما يتم تقييم مستويات تحصيل الطلاب في المدارس باستخدام أدوات وأسـاليب التقييم المتنوعاة، ومن

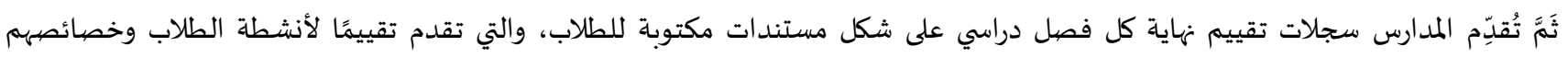

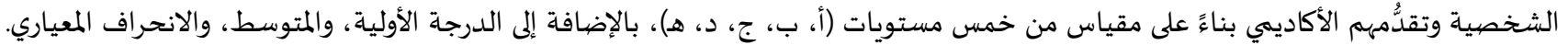

(Bouhlila,2011)

10.8.2 تأثير الدراسة الدولية TIMSS: شاركت كوريا الجنوبية في TIMSS ست مرات منذ عام 1995م، على الرغم من أن تأثير نتائج TIMSS كان واضحًا على السياسات التربوية

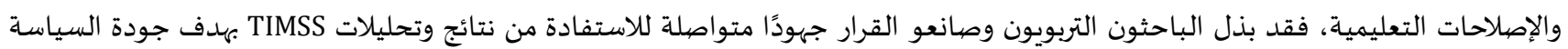
التعليمية الكورية على المستوى الوطني. (رشاد، 2014) كما استخدمت الباحثة الخطوة الثانية من أسلوب (بيرداي)، وهي (التحليل أو التفسير) لتفسير تطبيق الدراسة الدولية TIMSS في كل من

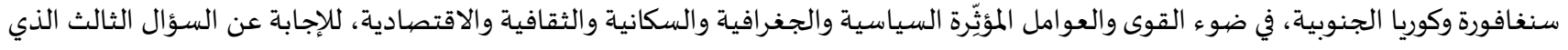

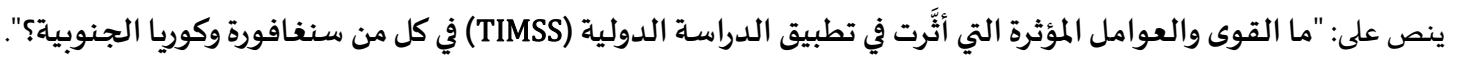
9.2. القوى والعوامل المؤثرة التي أثَّرت في تطبيق الدراسة الدولية (TIMSS) في سنغافورة:

1.9.2. العامل السياسي:

خضعت سنغافورة للاستعمار البريطاني، وتحوَّلت إلى قاعدة مهمة للأسطول البريطاني أثناء الحرب العالمية الثانية، ثم حصيلت على استقلالها،

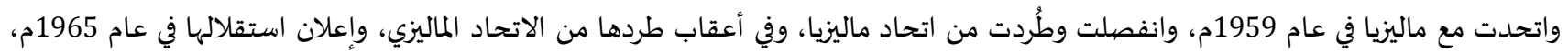
وجدت سنغافورة نفسها غارقة في مشكلات اجتماعية واقتصادية كثيرة، علاوة على البطالة وتدني مستوى التعليم، وتولى مهمَّة النهوض بسنغافورة

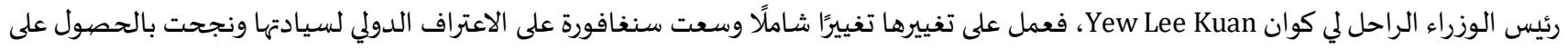

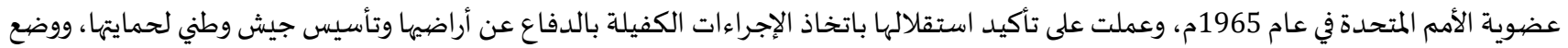

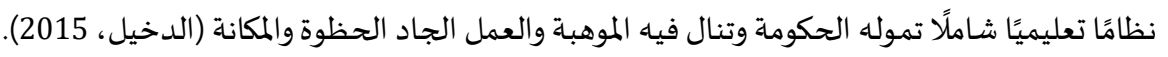

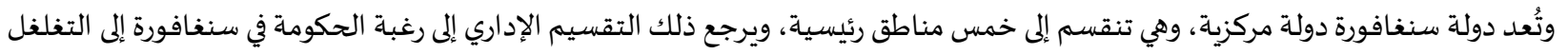

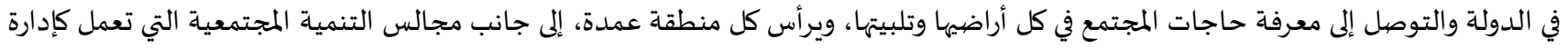
محلية، كما تضمى هذه المناطق مستوى آخر من العمل على المستوى المحلي، وهي البلديات، والتي يصل عددها إلى إلى 16 بلدية يقيم على كل منها مجلس إلس 
محلي تنفيذي، فطِن لي كوان Lee Kuan Yew إلى حقيقة أن التعليم عامل حاسم في لم شمل الجماعات العرقية والدينية المتنافرة والمتناحرة، وفي تطوير قوة عاملة من الطراز العالمي، لتحقيق الأهد اف الاقتصادياة التي رسمها لسنغافورة. (عمار، 2016)

2.9.2. العامل الجغرافي:

تقع جمهورية سنغافورة على المحيط الهندي، في جنوب شرقي آسيا، عند الطرف الجنوبي من شبه جزبرة الملايو، ويفصلها عن ماليزيا مضيق

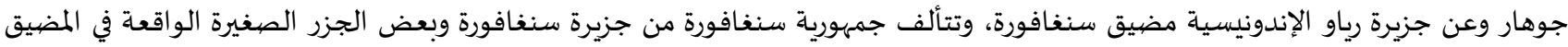

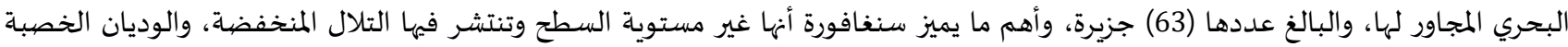

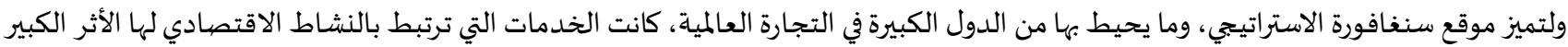
في زيادة الناتج المحلي. (Guo, 2015)

3.9.2 العامل السكاني: بلغ عدد سكان سنغافورة عام 2014م بنحو 5,469,700 وهي من الدول ذات الكثافة السكانية العالية في العالم نظرًا لصغر مساحتها، إذ تبلغ الكثافة السكانية 6112 نسمة في الكيلو متر المربع، وبلغ معدل النمو السكاني السنوي في نهاية الثمانينيات 1,9\%، وتعتبر هذه الزيادة أقل بكثير مما

كانت عليه في الأربعينيات والخمسينيات من القرن العشرين الميلادي عندما كانت نسبة المواليد تتعدى 4\%، وهي من أعلى النسب. (Djalal, 2015)

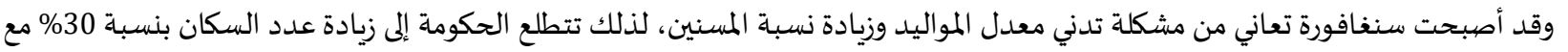

حلول 2030، ووضعت في عام 2001م خطة لمنح مكافأة مالية عن كل مولود جديد (الجرف، 2004م).

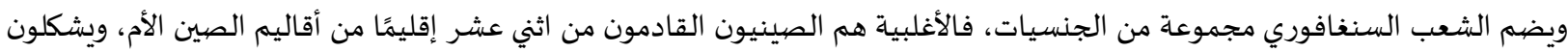
نسبة 76.3\% من السكان، أما الباقون فمن الملاويين، ويشكلون 15\%، والتاميلين من جنوب الهند ويمثلون 6.4\%، ثم الأوروبيون واليمنيون، ويمثلون

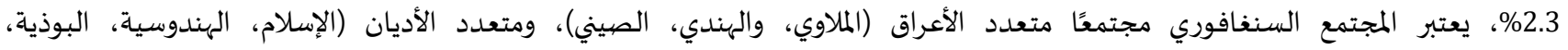
الكونفوشيوسية، الطاوية، المسيحية). (العبيدي، 2012) تعتبر سنغافورة بلد متعدد الديانات بسبب الخليط العرقي الموجود فياه، وتقر الدولة في سنغافورة بحرية الاعتقاد وفصل الدين عن الدولة فهي

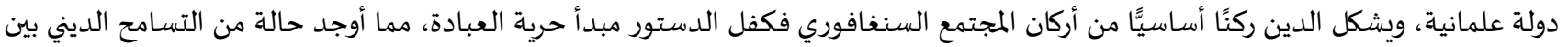

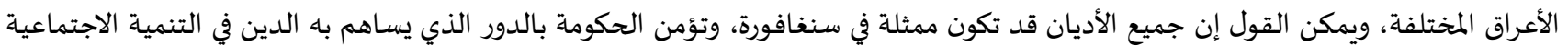
والاقتصادية لكل السكان ذات الأديان المتعددة والإسلام الدين الوحيد الذي حظي في سنغافورة بمجلس خاص مفوض بقانون برلماني هو المجلس

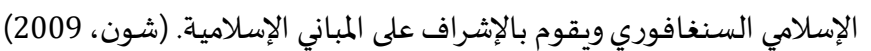
وهناك أربع لغات رسمية في سنغافورة وهي الإنجليزية، والصينية (الماندرين)، والماليزية، والتاميلية، وتعتبر اللغة الماليزية هي اللغة القومية للبلاد،

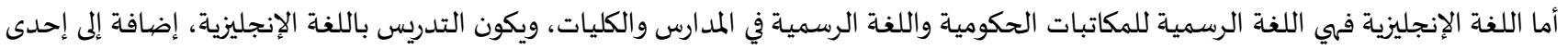

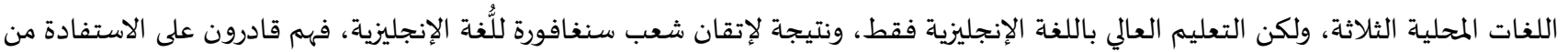
أحدث البرمجيات التي يتم التوصل إلها في العالم، حيث إن 80\% من محتوى شبكة الإنترنت مكتوب باللغة الإنجليزية. (Gopinathan, 2011)

5.9.2 العامل الاقتصبادي:

تمتلك سنغافورة تاسع أعلى احتياطي في العالم، كما تعتبر من النمور الآسيوية الرائدة، وتعد واحدة من أكثر الدول الاقتصادية انفتاحًا في العالم، وهي أسرع دولة في إنعاش اقتصادها بنمو وصل إلى 17.9\% عبر التركيز على زيادة الإنتاجية من خلال تعزيز المهارات والابتكار. (Djalal, 2015)

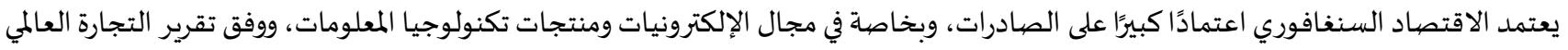

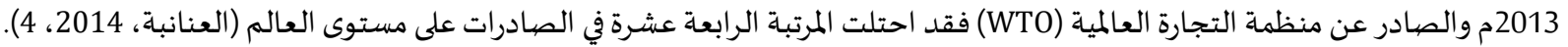

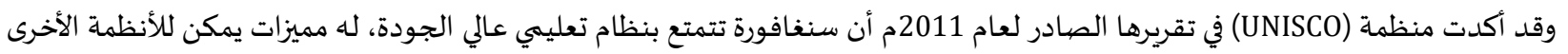

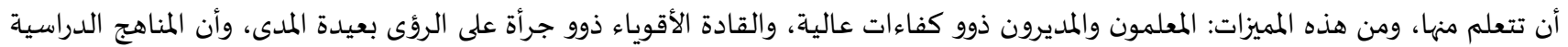
معدة بصورة جيدة وبمقاييس تتماشى مع أساليب التعليم الحديثة والقياس والتقويم. (UNISCO, 2011)

10.2. القوى والعوامل المؤثرة التي أثَّرت في تطبيق الدراسة الدولية (TIMSS) في كوريا الجنوبية:

1.10.2. العامل السياسي:

شكَّل تحرُّر كوريا الجنوبية من اليابان في عام 1945م، نقطة تحوُّل في تاريخها، وانتقلت إلى النظام الديمقراطي، وأصبح لديها حكومة تنقسم إلى ثلاثة فروع: السلطة التنفيذية والسلطة القضائية والسلطة التشريعية، حيث إن السلطتين التنفيذية والتشريعية تعملان في المقام الأول على الصعيد 
الوطني، أما السلطة القضائية فتعمل على المستويين الوطني والمحلي، كما استطاعت كوريا في فترة زمنية قصيرة أن تصبح من الدول الرائدة في مجال

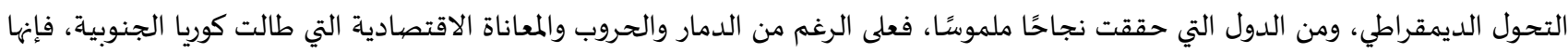
نجحت في التغلب على الأمية، وشهدت توسعًا كبيرًا في التعليم في الفترة 1950م التئ -

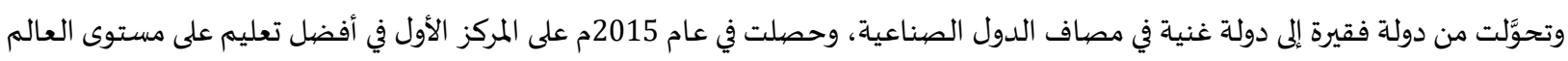

(Holderge,2018)

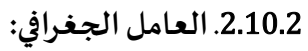

تحتل كوريا الجنوبية النصف الجنوبي من شبه الجزيرة الكورية في جنوب شرقي آسيا، وتغطي مساحة قدرها

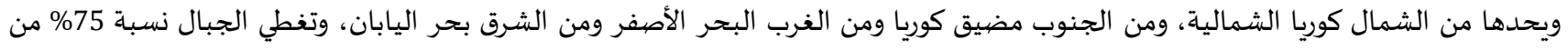

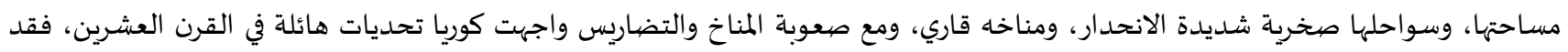

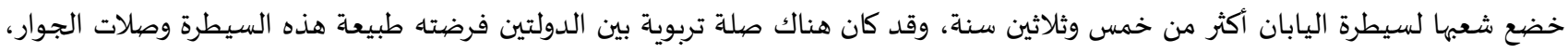

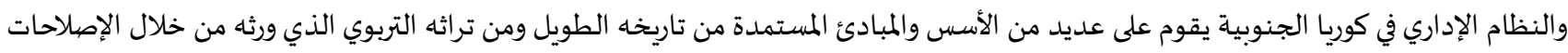

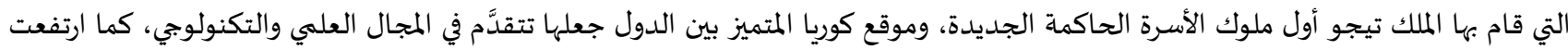

معدلات النمو في الإنتاج الاقتصادي. (البحيري، 2010)

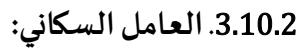

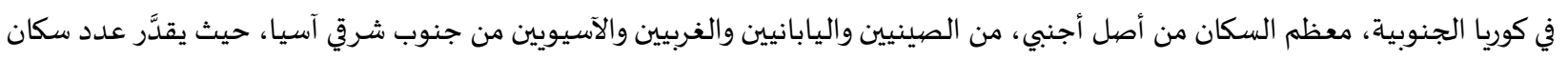

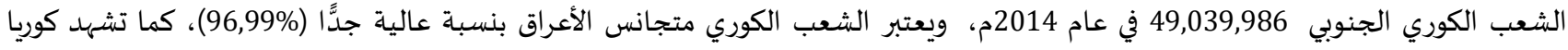

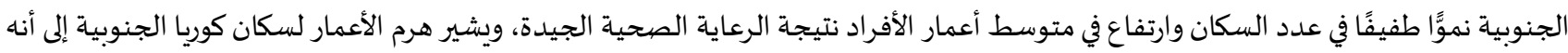

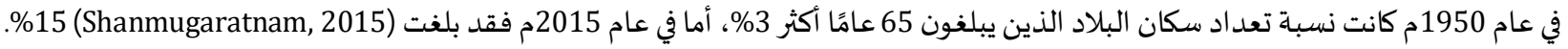

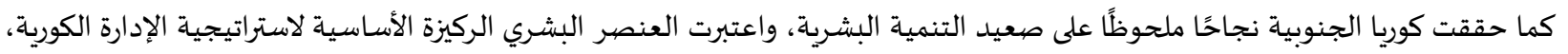

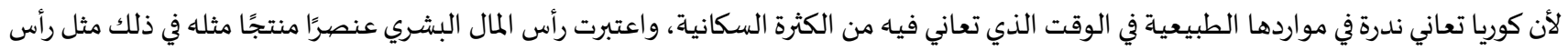

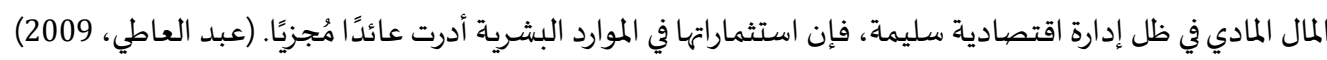

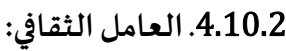

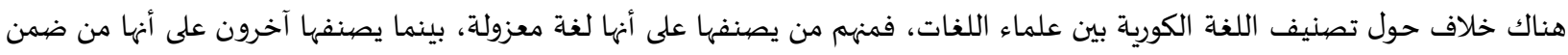

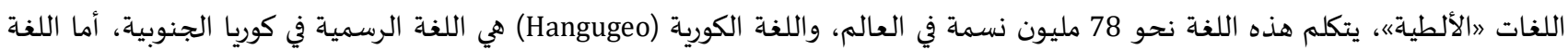
الإنجليزية، فمنتشرة بشكل واسع في كوريا الجنوبية وتدرَّس في جميع مراحل التعليم، كذلك تنتشر اللغات الصينية واليابانية والإسبانية، ويعتنق

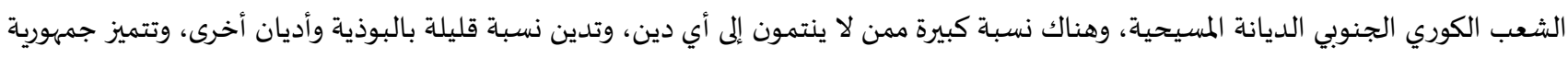

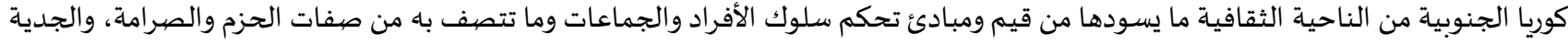

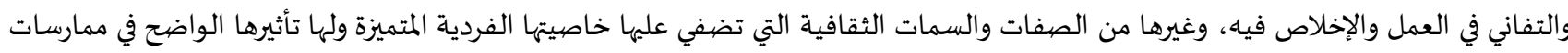

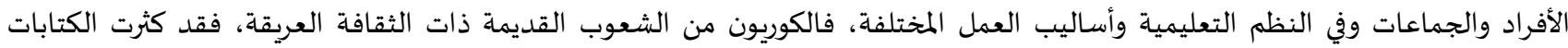

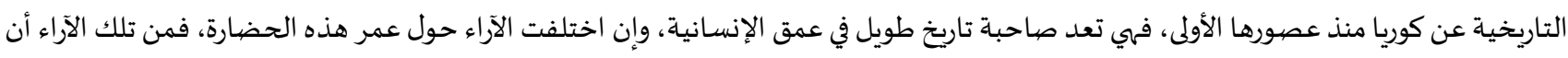

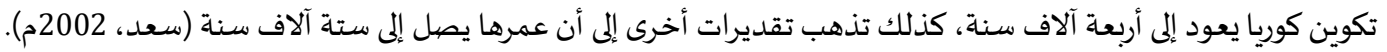

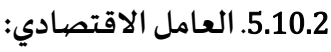

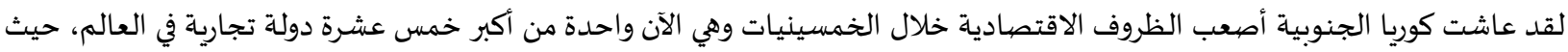

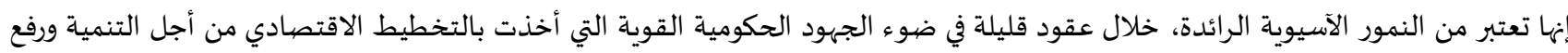

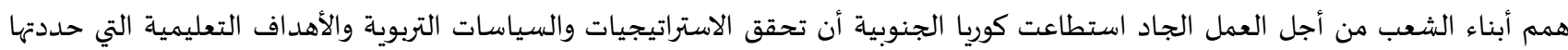

لتحقق ما يسميه الاقتصاديون المعجزة الكورية. (عبد العال، 2007)

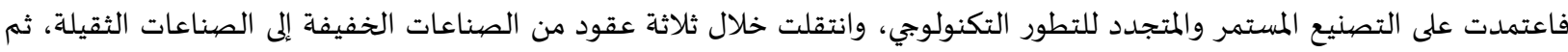

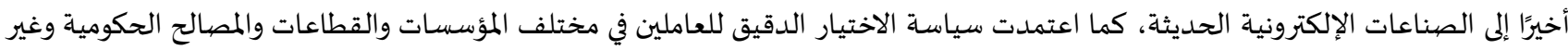

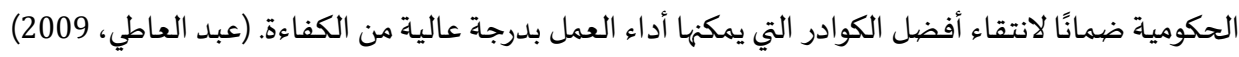
كما شهدت كوريا نموًا متزايدًا بالتكنولوجيا، وقد دعمت ذلك بعديد من الخطوات والسياسات التربوية والمزيد من التمويل. (2012, Seth)

Kaplan 
واستخدمت الباحثة الخطوة الثالثة من أسلوب (بيرداي)، وهي (الموازنة أو المناظرة) تحديد أوجه التشابه والاختلاف في تطبيق الدراسة الدولية TIMSS

السؤال الرابع الذي ينص على: "ما أوجه التشـابه والاختلاف في تطبيق الدراسـة الدولية (TIMSS) بين كل من سنغافورة وكوريا الجنوبية؟".

11.2. أوجه التشـابه والاختلاف في القوى والعوامل المؤثرة في كل من سنغافورة وكوريا الجنوبية:

1.11.2 العامل السياسي:

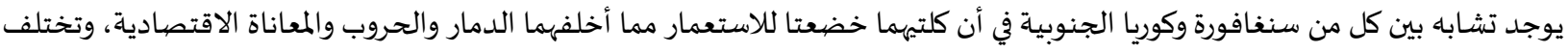
في أن سنغافورة كانت مستعمرة من إحدى الدول الأوروبية (بريطانيا)، بينما كوريا الجنوبية كانت مستعمرة من اليابان وهي من دول شرق آسيا، كما أنها

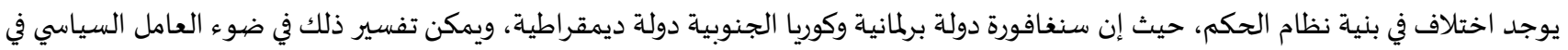

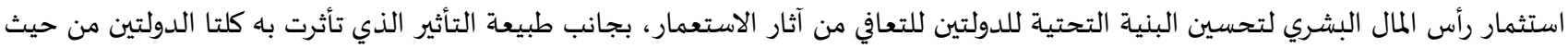
ثقافة المستعمر وتوجهاته. يضاف لما سبق الفترة التي حصلت فيها كل دولة من الدولتين على استقلالها، حيث حصلت سندانت سنغافورة على استقلالها عام 1965م، بينما تحررت

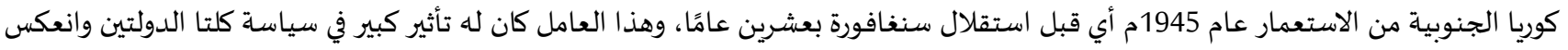

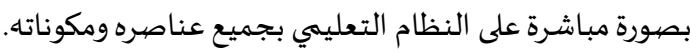
أما هذا العامل فهو مختلف تمامًا في المملكة العربية السعودية باعتبار أهها لم تقع تحت طائلة الاستعمار من جهاة، وبالتالي فهي لم تعانِ من تأثير

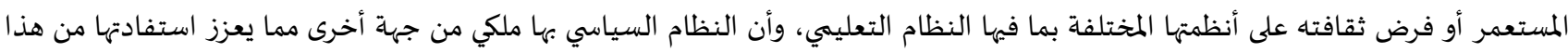
النظام في تطوير نظامها التعليمي بجميع عناصره، وهذا يُعد نقطة قوة للمملكة العربية السعودية.

2.11.2. يوجد تشابه بين كل من سنغافورة وكوريا الجنوبية في طبيعة تضاريسهما وصغر مساحتهما وموقعهما الجغرافي حيث إن كلتيهما تقعان في جنوب

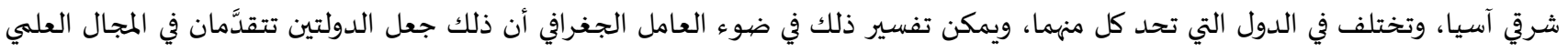
والتكنولوجي مما رفع معدل الناتج المحليّي للدولتين. وتختلف المملكة عنهما في هذا الأمر، خاصة من حيث معديث عامل المساحة باعتبارها أكبر منهما بكثير بالإضافة لاختلاف دول الجوار وتنوع الصلات

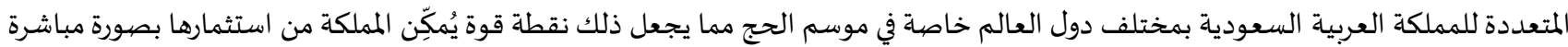
في تبادل الخبرات في شتى المجالات، بما في ذلك المجال المجال التعليمي.

3.11.2 يوجد تشاباء بين كل من سنغافورة وكوريا الجنوبية في كثافة سكانهما مقارنة بمساحتهما، وتعدد أعراق سكانهما، وتدني معدل المواليد وزيادة نسبة

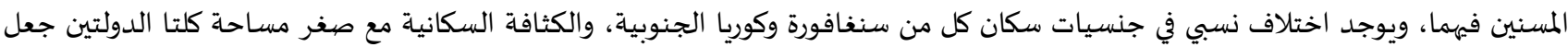

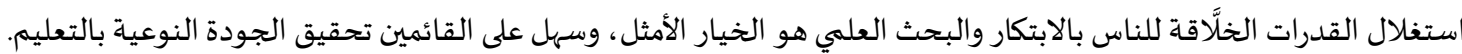

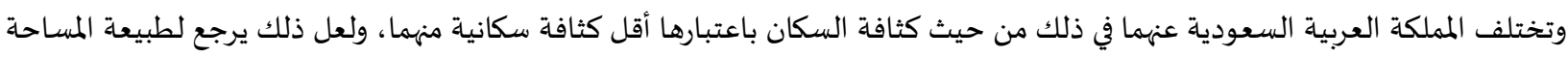

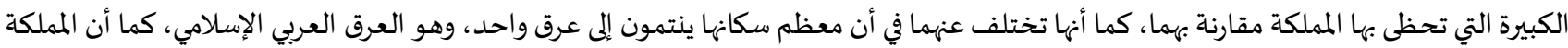

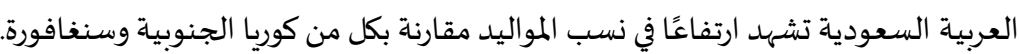

4.11.2 العامل الثقافي:

يوجد تشابه بين كل من سنغافورة وكوريا الجنوبية في تعدد اللغات والتسامح بين الأديان في كل منهما، وتختلف في أن سنغافورة دولة علمانية تكفل حرية الأديان، والإسلام الدين الوحيد الذي حظي في سنغافورة بمجلس خاص مفوض بقانون برلماني هو المجلس الإسلامي السنغافوري،

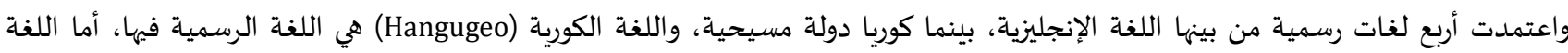

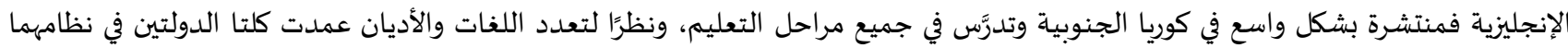
التعليمي إلى تعزيز الانتماء الوطني لدى طلابهم.

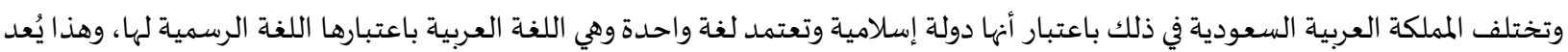
نقطة قوة تتميز بها المملكة العربية السعودية تبعًا لتميز اللغة العربية وثرائها من جهاة وتبعًا لعالمية الإسلام وتخطيه جميع الحدود المكانية والزمانية من

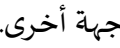


5.11.2 العامل الاقتصهادي:

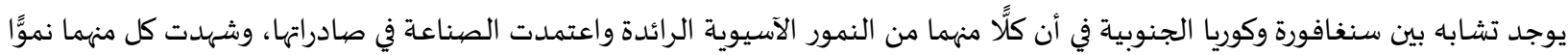

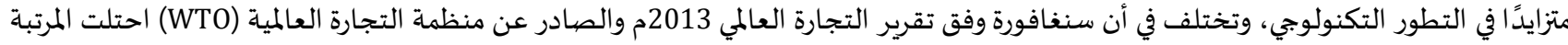

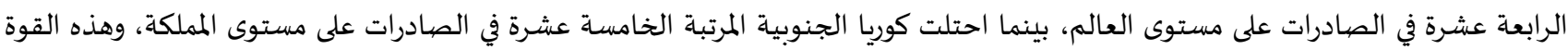
الاقتصادية في كل من الدولتين جعلت هناك تنمية للموارد البشرية وتطوير نظام التعليم وإنشاء البنية التحتية المعلوماتية وبنية الاتصالات.

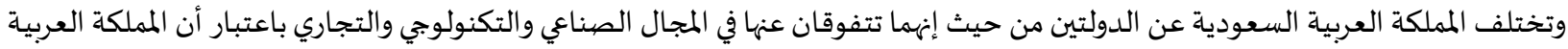

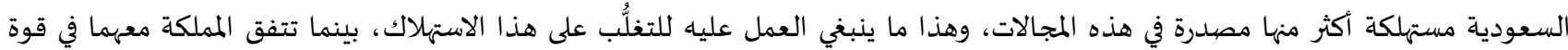
الاقتصهاد بصفة عامة مما يمثل نقطة قوة يمكن الاستفادة منها في تطوير أنظمتها المتعددة وفي مقدمتها النظام التعليهي بجميع عناصره ومكوناته.

12.2. أوجه التشابه والاختلاف في و اقع تطبيق الدراسة الدولية TIMSS في كل من سنغافورة وكوريا الجنوبية:

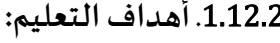

يوجد تشابه بين كل من سنغافورة وكوريا الجنوبية في الاهتمام بالتعليم والمدارس المهنية وتشجيع البحث العلمي، بينما تختلف كوريا الجنوبية عن

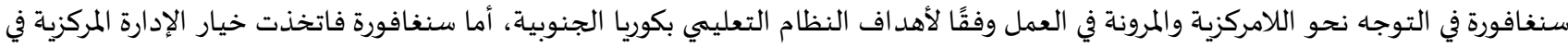

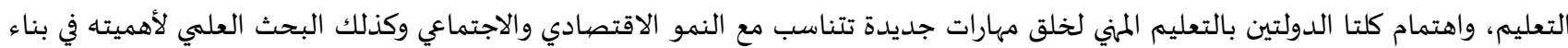
المعرفة وتيسير التعلُّم. ويمكن للمملكة الاستفادة من تطبيق النظام اللامركزي المتبع بكوريا الجنوبية باعتباره نقطة قوة يسهم تطبيقها في تطوير النظام التعليهي، كما

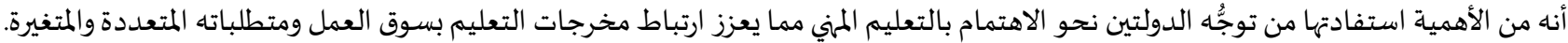

13.2. منهج الرياضيات في المرحلة الابتدائية والمتوسطة:

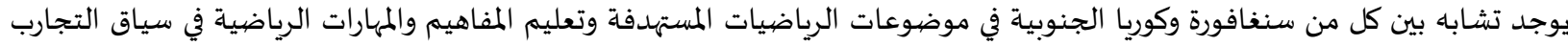

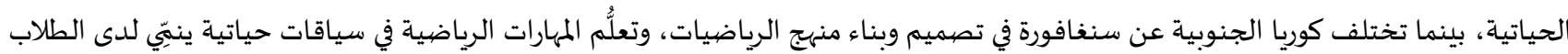
القدرة على التفكير وتنمية الإدراك عندهم وأدعى لبقاء أثر التعلُّم.

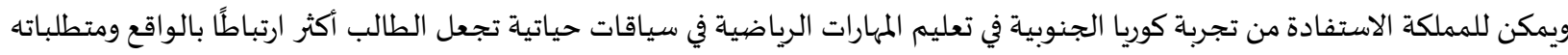

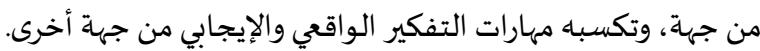

14.2. منهج العلوم في المرحلة الابتدائية والمتوسطة: يوجد تشابه بين كل من سنغافورة وكوريا الجنوبية في موضوعات العلوم المستهدفة وتعليم مفاهيم ومهارات العلوم في سياق الظواهر الطبيعية،

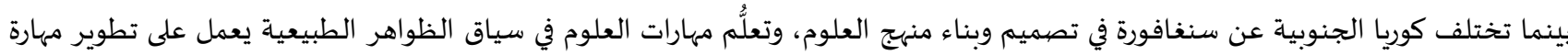
التحليل والتفكير الناقد لدى الطلاب، وحب الاطاع والإن الاستقصاء العلمي.

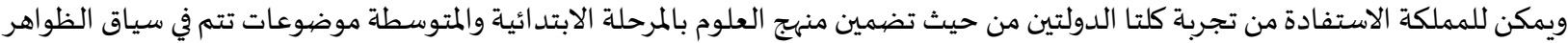

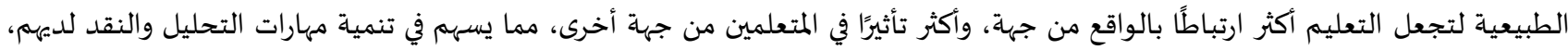

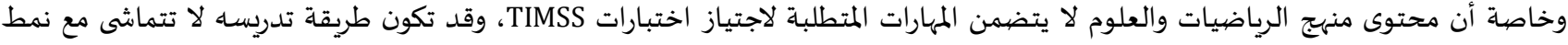

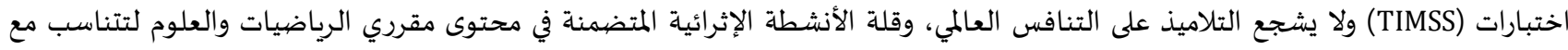

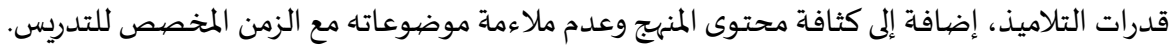

15.2. مبادرات في تعليم الرياضيات والعلوم:

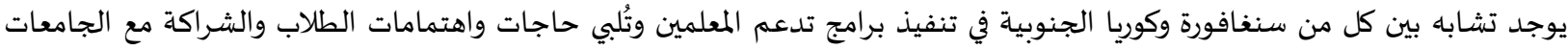

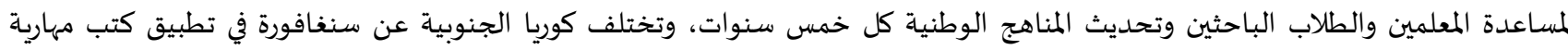

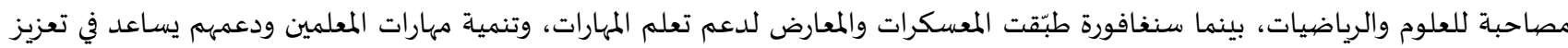

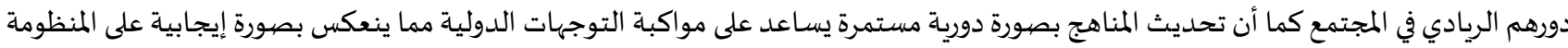
التعليمية. ويمكن للمملكة الاستفادة من هذه المبادرات في تعزيز وتطوير تعليم الرياضيات والعلوم بما يتناسب مع الظروف والإمكانات المتاحة لها وفي ضوء طبيعة المتعلمين واحتياجاتهم وما يمتلكونه من إمكانات واستعدادادات. 
16.2. مؤهلات معلم الرياضيات والعلوم:

يوجد تشاباء بين كل من سنغافورة وكوريا الجنوبية في اشتراط درجة البكالوريوس ودبلوم دراسات عليا، وتختلف كوريا عن سنغافورة في اجتياز المعلم لاختبار التوظيف، بينما سنغافورة لا بد على المعلم أن يجتاز الحد الأدنى من برنامج التدريب قبل مباشرة العمل، وهذا تبرز في كلتا الدولتين

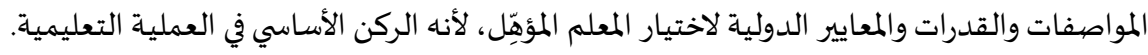

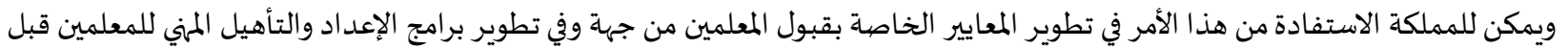
العمل وتطوير برامج التنمية المهنية لهم أثناء العمل.

17.2. متطلبات التطوير المهني المستمر للمعلم:

يوجد تشابا بين سنغافورة وكوريا الجنوبية في اشتراط عدد ساعات معينة في التطوير المهني للمعلم في العام الدراسي، وتختلف كوريا عن

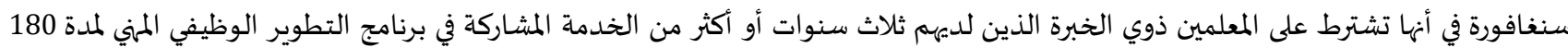
ساعة خلال إجازاتهم الصيفية للتأهل للحصول على شهادة معلم في المدرسة من الدرجة الأولى، وهذا التطوير المهني يسهم في رفد المعلمين بمهارات

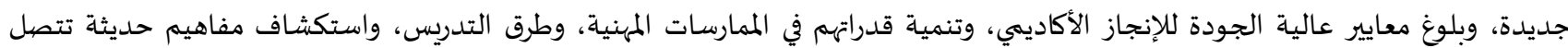
بالمحتوى العلمي الذي يُقدَّم للطلاب. ويمكن للمملكة الاستفادة من ذلك فيما يتعلق ببرامج التنمية المهنية للمعلمين من حيث محتواها وخططها والمدة الزمنية المقررة لها في ضوء ما

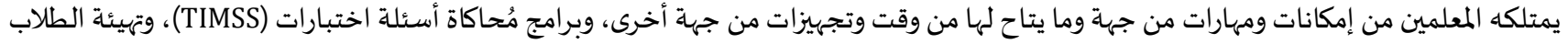

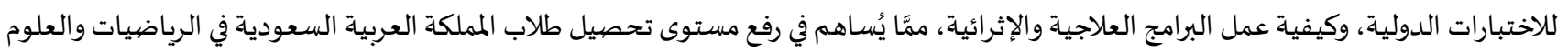

في ضوء نتائج اختبارات (TIMSS).

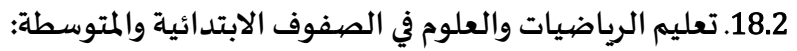
يوجد تشابه بين سنغافورة وكوريا الجنوبية في تعليم الطلاب من قبل معلمين متخصصين في الرياضيات والعلوم، وتختلف كوريا عن سنغافوروة بأنه يتم تدريس طلاب المرحلة الابتدائية من قبل "معلمي الفصل"، أما طلاب المرحلة المتوسطة فيتم تدريسهم من قبل "معلمي المادة"، فالمعلم

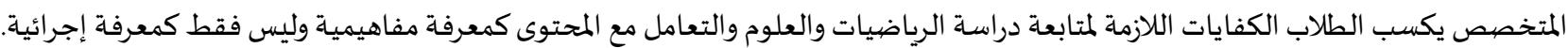

19.2. استخدام التكنولوجيا: كل من دولتي المقارنة تستخدم الآلات الحاسبة مع التركيز على الحسابات الذهنية واليدوية واستخدام التكنولوجيا في تعميق فهم المفاهيم والأسس الرياضية كذلك في دعم تعلم مهارات العلوم، وهذا يؤدي إلى دعم وتطوير فهم الطلاب للمفاهيم والعلاقات الرياضية والتحقق من العمليات

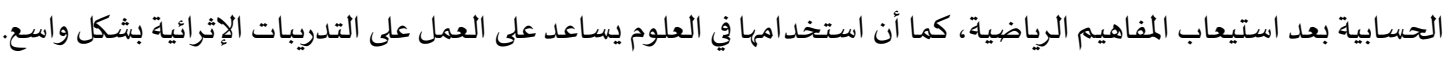
ويمكن للمملكة الاستفادة من تجربة كلتا الدولتين في هذا الجانب من خلال التوسع في استخدام التقنيات والمستحدثات التكنولوجية وتوظيفها

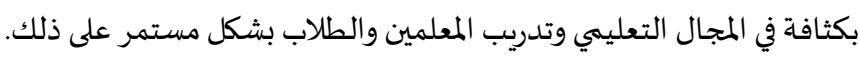

20.2. تقييم الطلاب في الرياضيات والعلوم:

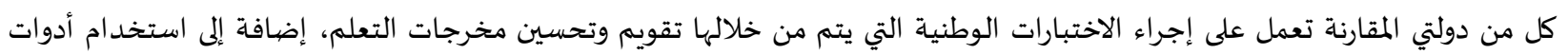
وأساليب التقويم المتنوعة، وهذا يؤدي إلى قياس جوانب التعلم المختلفة ومهارات التفكير العليا لدى الطلاب.

تأثير الدراسـة الدولية TIMSS: كل من دولتي المقارنة تستخدم بيانات المشاركة في الدراسة الدولية TIMSS لتحديد نقاط القوة والضعف مثل الأخطاء الشائعة وصعوبات التعلم لابتكار طرق للتدريس والتعلم لمعالجة صعوبات تعلم الطلاب التي حددنها الدراسة، كما تستخدم تلك البيانات لمراجعة السياسات التربوية والبرامج التعليمياة، مما ساعد على تحسين مستوى التعليم لدى دولتي المقارنة. وقد استخدمت الباحثة الخطوة الرابعة (المقارنة) لاستخلاص أوجه الإفادة من خبرات دولتي المقارنة (سنغافورة وكوريا الجنوبية) في تطبيق دارسة

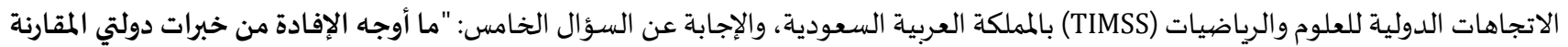

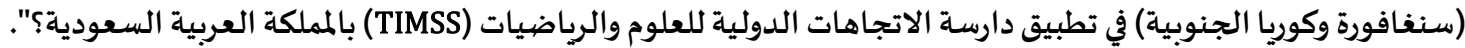
21.2. و اقع تطبيق دارسة الاتجاهات الدولية للعلوم والرياضيات (TIMSS) للصف الر ابع والصف الثاني المتوسط بالمملكة العربية السعودية: سنشير إلى ذلك كما يلي: (العقالي والجهني، 2019) من أبرزأهداف التعليم بالمملكة وفق برنامج التحول الوطني 2020: ضممان التعليم الجيد والمنصف والشـامل للجميع وتعزيز فرص التعلم مدى الحياة. تطوير المناهج وأساليب التعليم والتقويم. 


\section{تحسين استقطاب المعلمين وتأهيلهم وتطويرهم. \\ تعزيز القيم والمهارات للطلاب. \\ تعزيز قدرة نظام التعليم والتدريب لتلبية متطلبات التنمية واحتياجات سوق العمل.}

1.21.2. منهج الرياضيات والعلوم في المرحلة الابتدائية والمتوسطة:

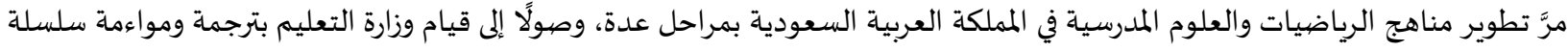

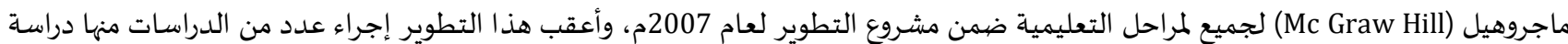

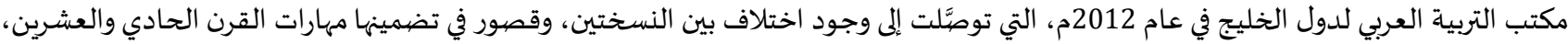

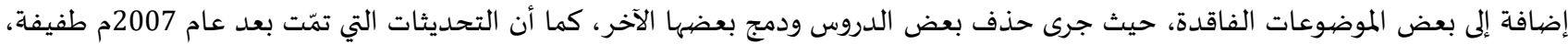
وليست تطويرًا جذريًا لمنهجي الرياضيات والعلوم. (خليل، 2019 2016) وقد أشارت دراسة (بدر، 2016) عند تحليل محتوى كتاب الرياضيات للصاضيات الريات الرابع بالمملكة وفق متطلبات TIMSS إلى أنه يوجد ارتفاع في مجال

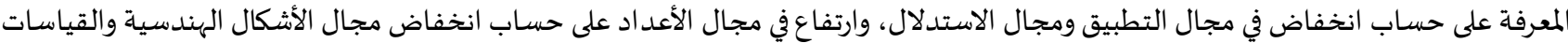
وعرض البيانات. كما توصلت دراسة (العنزي والرويلي، 2018) عند تحليل كتاب العلوم للصف الثاني المتوسط بالمملكة وفق متطلبات TIMSS إلى أن مجال

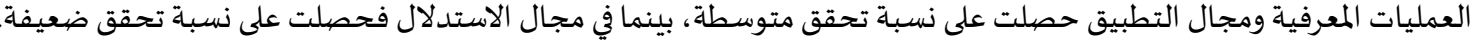
كما أشارت الهيئة الدولية لتقويم التحصيل التربوي (IEA) إلى التدني في مستوى تحصيل طلاب المملكة بالصف الثانية الثاني المتوسط في اختبار لمادة الرياضيات، وقد أوصى عديد من الدراسات بضرورة تضمين مناهج الرياضيات والعلوم لمتطلبات الدروات دراسة التوجهات الدولية في الرياضيات والعلوم TIMSS مثل دراسة (بدر، 2016؛ البلوي، 2016؛ الشهري، 2017؛ الترات الحبيب 2019).

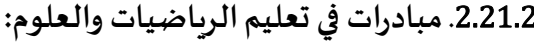
إطلاق المسابقات الوطنية مثل الأولمبياد الوطني للعلوم والرياضيات، والتوسع في افتتاح مراكز (STEM) المدرسية، فقد تم افتيات المتاح (104) مراكز في

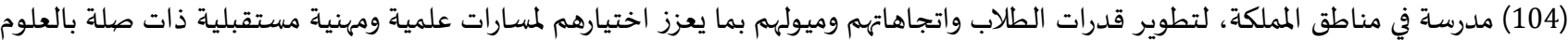

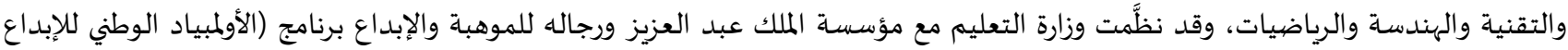

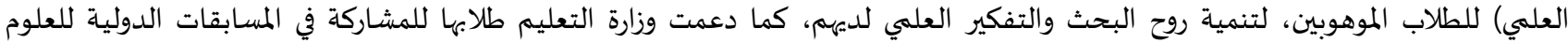
والرياضيات والهندسة وجعلت عمل البحوث العلمية والإجرائية أحد معايير الفوز بجوائز تميز المعلم، كذلك من مهام المعلم إثراء الطلاب المتميزين المعابين ودعم الطلاب ذوي المستوى المنخفض وعمل برامج علاجية لهمه

3.21.2 مؤهلات معلم الرياضيات والعلوم:

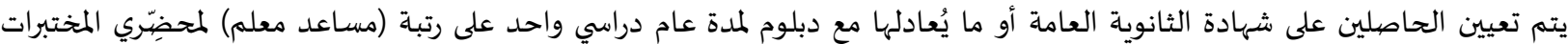

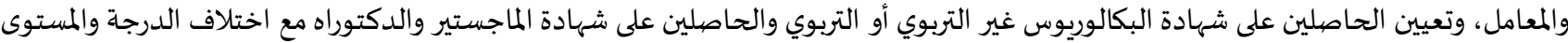

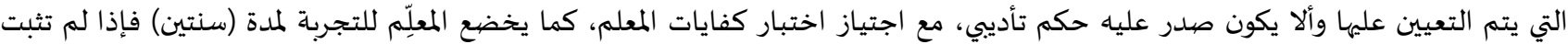

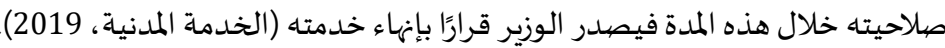

4.21.2 - 4.2 متطلبات التطوير الممني المستمر للمعلم: يتطلب اجتياز اختبار الرخصة المهنية للمعلمين، وهو عبارة عن اختبارات مقننة لقياس القدرات التربوية والتخصصية للمعبلميني، مبنية على

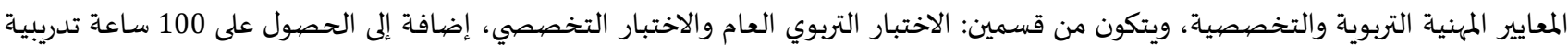

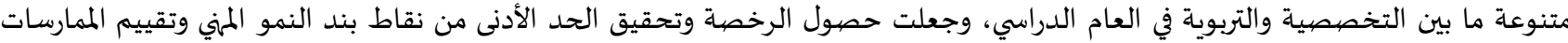

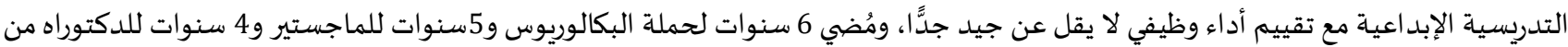
معايير ترقية المعلم.

5.21.2. تعليم الرياضيات والعلوم في الصفوف الابتدائية والمتوسطة:

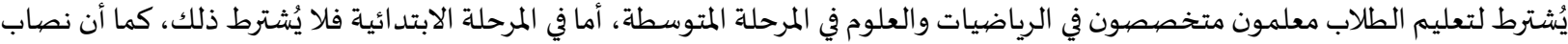

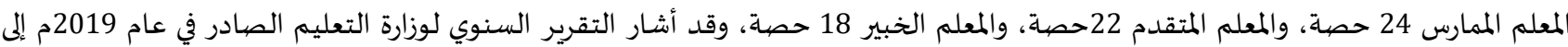

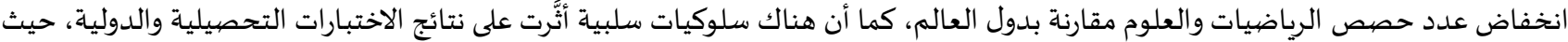
إن الطلاب لديهم اهتمام ضعيف بالقراءة ويغيبون ويتأخرون مرة واحدة في الأسبوع على الأقل ويُتنمَّر عليهم. 


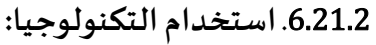

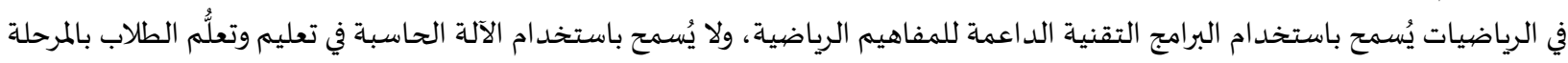

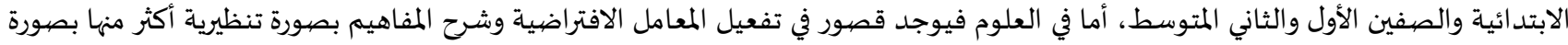

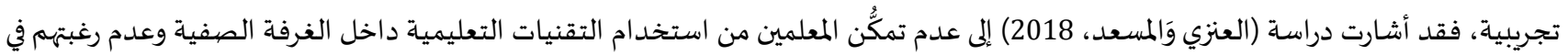
التغيير في أنماط التدريس واعتمادهم على الطرق التقليدية في الشرح.

7.21.2. تقييم الطلاب في الرياضيات والعلوم في الصفوف الابتدائية والمتوسطة:

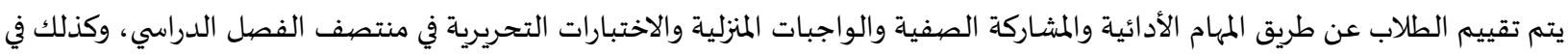

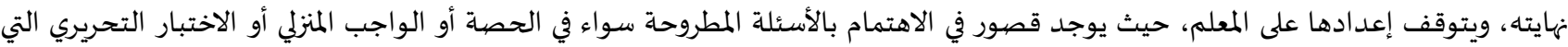

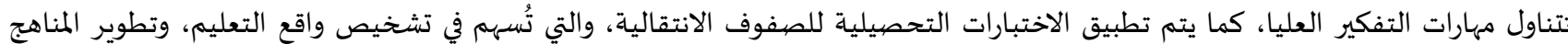
الدراسية، والممارسات التدريسية وبناء برامج التطوير الممني للمعلمين وتأهيلهم.

8.21.2 تأثير الدراسة الدولية TIMSS:

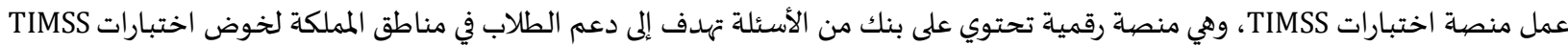

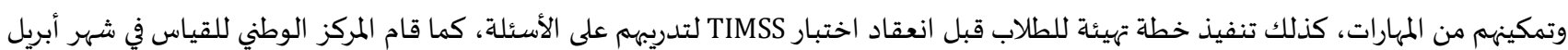

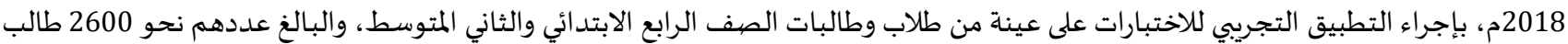

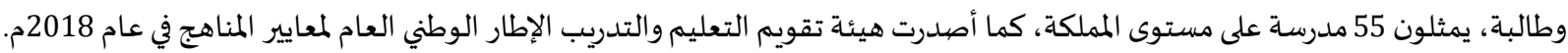
أوجه الإفادة من خبرات دولتي المقارنة (سنغافورة وكوريا الجنوبية) في تطبيق دارسة الاتجاهات الدولية للعلوم والرياضيات (TIMSS) بالمملكة

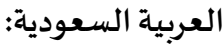

استثمار نتائج الدراسة الدولية TIMSS في إصلاح النظام التعليمي بمفهومه الشامل وليس فقط تهيئة الطلاب قبل موعد الاختبار. التركيز على جودة النوع لا الكم، وإعادة النظر في المناهج الدراسية المحشوة بالمعلومات لإفساح المجال أمام الطلاب للتفكير، والسعي لأن تكون طرق التدريس تتمحور حول الطالب. إعطاء مهارات التفكير الناقد أولوية في المناهج الدراسية، وتطوير قدرات المعلمين لتدريسه وإكسابهم القدرة على قياس وتقييم مهارات التفكير الناقد لدى طلابهم. تخفيف نصاب الحصص لمعلم الرياضيات والعلوم، لتحقيقهم التقويم والتواصل الأمثل مع الطلاب.

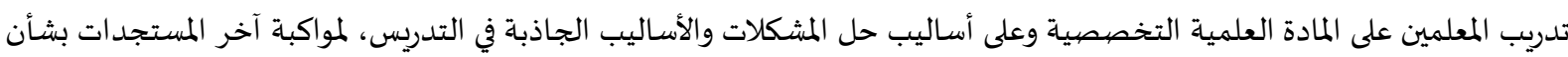
معرفة المحتوى والابتكارات التربوية وأساليب التقييم الجديدة. تحسين ممارسات المملمين في تقويم الطلاب من خلال استخدام أساليب وأدوات التقييم المتنوعة بما يتسق مع المعايير الدولية وجداول المواصفات.

الاستعانة بالوسائل التعليمية والتكنولوجية الحديثة التي تتيح التنوع في طرق تدريس المناهج خاصة ما يكون تجريبيًا منها.

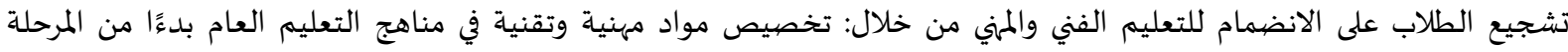

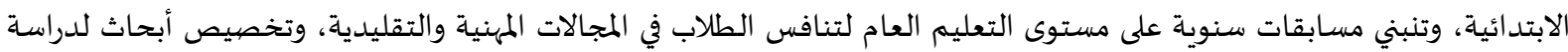
أساليب استقطاب الطلاب للتخصص في المجالات التقنية والمهنية.

المراجعة المستمرة لنظام التعليم، ليُلائم متغيرات العصر، والقائم على أحدث الأساليب العلمية والتكنولوجية. تطوير مناهج الرياضيات والعلوم بصفة دورية مستمرة وتضمينها الفاقد من الموضوعات ومهارات القرن الحادي والعشرين لتواكب الاتجاه العالمي في التعليم وبما يتوافق مع متطلبات سوق العمل. تخطيط البرامج التدرببية المقدَّمة للمعلمين في ضوء احتياجياتهم المهنية، وطبيعة مادة التدريس وأهداف التعليم، وخصائص نمو الطلاب. إسناد تدريس منهج الرياضيات والعلوم لمعلمات التخصص بدءًا من رياض الأطفال. زيادة حصص الرياضيات والعلوم لتحسين معارف ومهارات الطلاب فيهما وفق توجُهات المجتمعات المتقدِّمة. تبنيّ رؤية جديدة خاصة بإعداد المعلم في مجتمع المعرفة، وكذلك سياسات قبول المعلمين تضمن ترشيح ذوي الكفاءات من المتقدِّمين. 
التوجّه نحو الاقتصاد القائم على المعرفة، والتركيز على مراكز البحث العلمي والابتكار، والتي تعتبر حجر الزاوية لاقتصهاد المعرفة، وعقد الشراكات مع الجامعات ومراكز العلوم والتكنولوجيا لتحفيز المعلمين والطلاب الباحثين.

تبني مبادرات وزارية متعددة لإثراء الطلاب المتميزين ودعم الطلاب ذوي المستوى المتوسط ومعالجة الطلاب ذوي المستوى المنخفض في

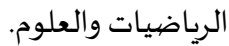

تهيئة البيئة الصفية بالوسائل التعليمية والمستحدثات التكنولوجية الداعمة للعملية التعليمياة.

أولًا: المراجع العربية:

1. إيشي، ماساكو (2006). الفلبين وتايلاند وسنغافورة وبروما وكمبوديا ولاروس منذ بد/يات القرن العشسين إلى الحاضر (ترجمة: بثينة الناصهري)، في (جوزيف سعاد): موسوعة النشاء والثقافات الإسلامية، مؤسسة المرأة والذاكرة، القاهرة.

2. البحيري، خالد (2010). التعليم الأساسي في كل من سلطنة عمان وكوريا الجنوبية، دراسة مقارنة. وزارة التربية والتعليم، (30): 54-67. 3. بدر، بثينة محمد بن حمود (2016). تحليل محتوى كتاب الرياضيات للصف الرابع الابتدائي بالمملكة العربية السعودية وفقا لمتطلبات دراسة فئة التوجهات الدولية للرياضيات والعلوم TIMSS، المجلة التوبوية: الكوبيت، 31 (121): 209 -258. 4. البلوي، عايد علي محمد (2016). تحليل محتوى كتاب الرياضيات للصف الرابع الابتدائي في المملكة العربية السعودية وفق متطلبات الدولية الدراسة الدولية للرياضيات والعلوم TIMSS2011، مجلة جامعة طيبة (العلوم التويوية): السعودية.

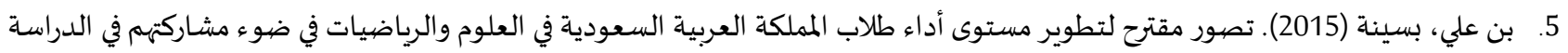

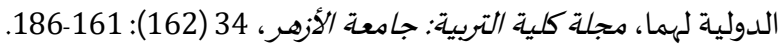
6. بورسلي، نورا وليد (2018). طبيعة السياسة التعليمية في المرحلة الثانوية في كل من سنغافورة وفنلندا: تحليل وثائق، المجلة التربوية: جامعة الكوبت، مجلس النشر العلهي، 33 (129): 15-64.

7 7. تان، شارلين (2010). مسارات سياسة التعليم في عصر العولملة، شواهد من سنغافورة وكمبوديا، مجلة مستقبليات (مركز مطبوعات اليونسكو)، القاهرة، 4 (4): 8. الجرف، ريما سعد (2004). البعد العالمي في مناهج الدراسات الاجتماعية للمبحلة الثانوية في سنغافورة (ندوة المناهج: الأسس والمنطلقات). كلية التربية، جامعة الملك سعود، الرياض، 2.

9. الجندي، حسن عوض حسن وَخليل، إبراهيم بن الحسين (2019). استخدام استراتيجية تدريسية قائمة على البراعة الرياضية في تنمية التحصيل الدراسي وفقًا للاختبارات الدولية TIMSS وتقدير الذات الرياضي لدى تلاميذ المرحلة الابتدائية، مجلة تربويات الرياضيات: الجمعية لترية المصبرية لتوبويات الرياضيات. 22 (12): 67-131.

10. الحبيب، محمد إبراهيم (2019). تقييم محتوى كتاب الرياضيات للصفيف الرابع الابتدائي في المملكة العربية السعودية في ضوء متطلبات دراسة التوجهات الدولية في الرياضيات والعلوم 2011 TIMSS، المجلة التويوية: جامعة سوهاج، 62: 533-575. 11. الحصان، أماني (2015). مدى تحقيق متطلبات مشروع التوجهات الدولية للدراسة في كتاب العلوم من الصف الأول الأول إلى الرابع

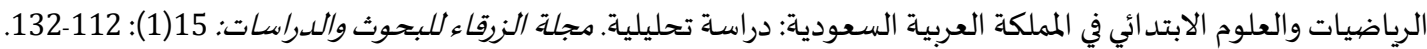
12. خليل، نبيل سعد (2002). إدارة التعليم في جمهورية كوريا الجنوبية وإمكانية الإفادة منها في تطوير إدارة التعليم في مصر"، مجلة كلية التربية: 36-34:

13. الدخيل، عزام محمد (2014). نظرة في تعليم الدول العشر الأوائل في مجال التعليم عبر تعليمهم الأساسي. الدار العبربية للعلوم، ناشرون، بيروت.

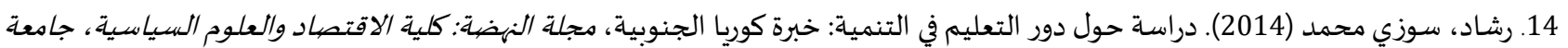
القاهرة، 15 (4): 35-60.

15. الرشيدي، غازي عنيزان (2017). الملامح المميزة لنظام التعليم في سنغافورة، وإمكانية الإفادة منها في دولة الكويت: دراسة تحليلية، مجلة كلية

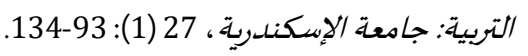
16. الرويلي، فارس قيّاض والعنزي، فياض حامد (2018). تحليل محتوى مقرر العلوم للصف التهائ، الثاني المتوسط في المملكة العربية السعودية في ضوء متطلّبات دراسة (TIMSS). مجلة الحكمة للدراسات التربوية والنفسية: (15). 17. الشربيني، أسامة إسماعيل (2018). مجتمع المعرفة في كل من سنغافورة والصين وكيفية الإفادة منها في جمهورية مصر العربية: دراسة مقارنة.

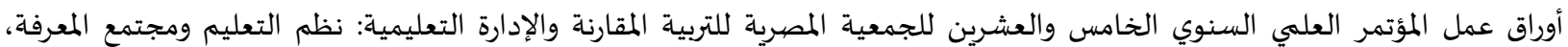
الجمعية المصرية للتربية المقارنة والإدارة التعليمية، 15-82. 
18. الشمراني، صالح، سعيد البرصان، الدوراني، إسماعيل سلامة (2016). إضاءات حول نتائج دول الخليج في دراسة التوجهات الدولية في

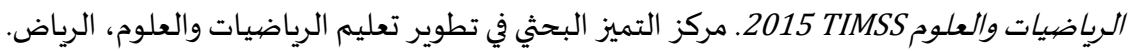

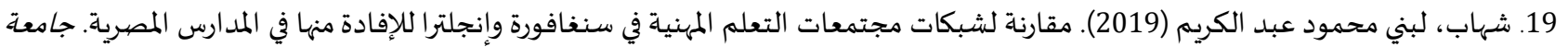

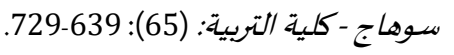

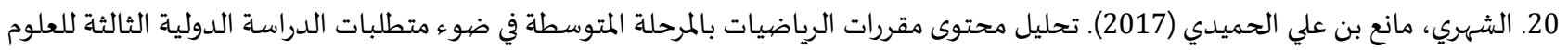

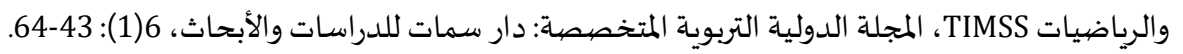

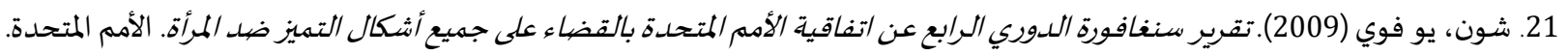

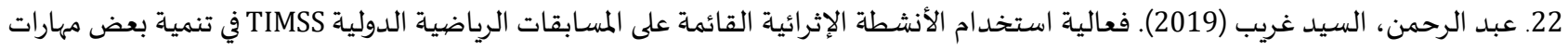

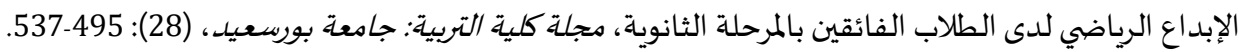

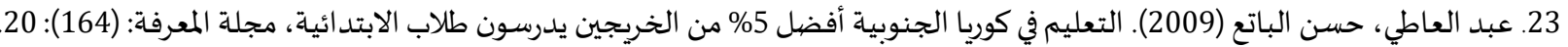

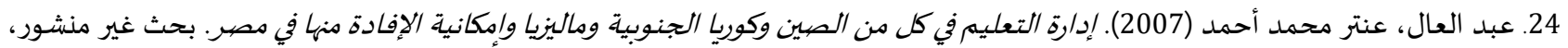
جامعة سوهاج: كلية التربية. 25. العقالي، أماني، الجهني، زهور (2019). فاعلية برنامج إشرافي يستند إلى الدراسة الدولية TIMSS في تنمية مهارات التفكير الرياضي لدئ الطاليات الماتية

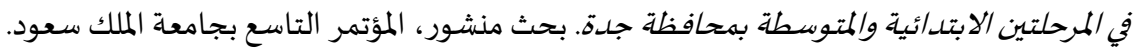

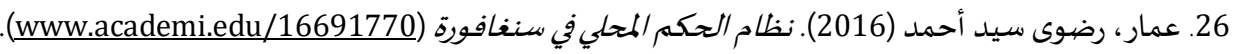
27. العنانبة، أحمد محمد (2014). دراسة تحليلية لواقع التجارة الخارجية بين دولة الإمارات العببية المتحدة وجمهيورية سنغافورة. إدارة التحليل والمعلومات التجارية، وزارة الاقتصاد، أبو ظبي.

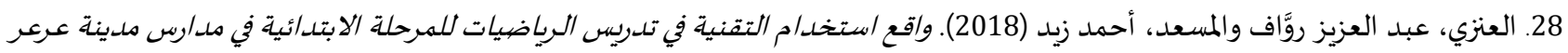
من وجهة نظر المعلمين والمعلمات. مجلة العلوم التربوية والنفسية: 2 (23).

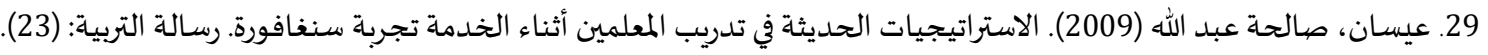

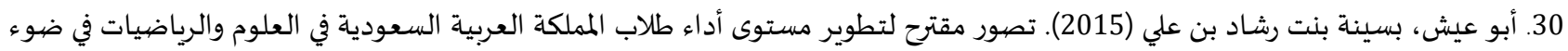

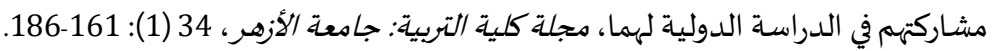
31. الغامدي، منى سعيد (2018). تقييم كتب الرياضيات والتمارين المطوَّرة للصفوف من الأول حتى الرابع الابتدائي في المملكة العربية السعودية في

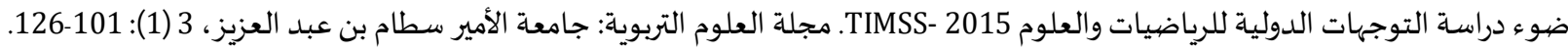

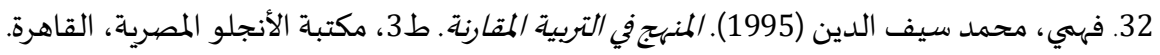

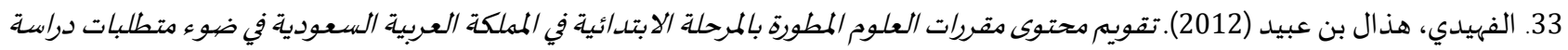
التوجهات الدولية TIMSS. رسالة دكتوراه غير منشورة، جامعة أم القرى، السعودية.

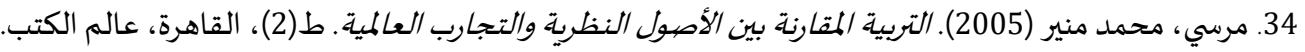

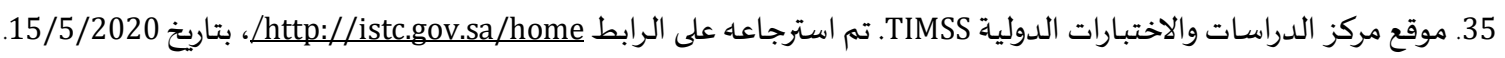

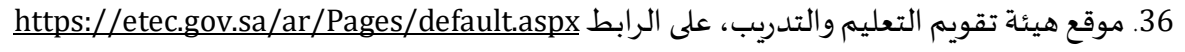

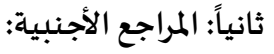

1. Bouhlila, D (2011). The Quality of Secondry Education in the Middle East and North Africa :what Can We Learn from (TIMSS) Results Compare. A Journal of Comparative and International Education, 41(3): 327-352 https://doi.org/10.1080/03057925.2010.539887

2. Djalal, Dinisari (2015). Singapore, World Bank Group Respond to Global Demand and Establish Major Infrastructure and Urban Development Hub. World Bank Group, Ministry of Finance, Singapore.

3. Dodeen, Hamzeh, Abdelfattah, Faisal, Shumrani, Saleh \& Abu Hilal Maher, (2012). The Effects of Teachers' Qualifications, Practices, and Perceptions on Student Achievement in TIMSS Mathematics: A Comparison of Two Countries. International Journal of Testing, 12(1): 61-77. https://doi.org/10.1080/15305058.2011.621568

4. Early Childhood Development Agency, Singapore (2013). Early years development framework for childcare centres. Retrieved

5. Goh, C. T (1997). Speech by Prime Minister Goh Chok Tong at the opening of the 7th international conference on thinking. Retrieved from http://www.moe.gov.sg/media/speeches/1997/020697.htm

6. Gopinnathan, S (2011). The Education System in Singapore the Key to its Success, National Institute of Education, Singapore. 
7. Guo, Wanda (2015). Global Financial Centers index 18, (www.longfinances.net/images/GFCI 18-23 Sep 2015.Pdf)

8. Holderge, Barbara, A (2018). Intrrrogating the Comparative Method: Whither, Why and How? Religions, 9(58). https://doi.org/10.3390/rel9020058

9. Huang, Min \& Bond, Francis (2016). Comparison and contrast of Chinese curricula between China and Singapore: challenges and prospects. Asian-Pacific Journal of Second and Foreign Language Education. 1. https://doi.org/10.1186/s40862-016-0023-6

10. Kovaleva. G (2010). The TIMSS Study the Quality of Education im mathematics and natural Scince in Russi exceeds average international indicators. Russian Education and Socity, 52 (11): 72-89. https://doi.org/10.2753/res1060-9393521106

11. Ministry of Education, Singapore (2015). About us. Retrieved from http://www.moe.gov.sg/about/

12. Mullis, I.V.S., \& Martin, M.O (Eds) (2019). TIMSS Advanced 2019 assessment frameworks. Chestnut Hill, MA: Boston College.

13. Mullis, I.V.S., \& Martin, O.M., Ruddock, G.R. Chrisine, Y., O. Corinna. Preush (2009). TIMSS 2011 Assessment framework TIMSS and PIRLS International Study Center. Bosten College.

14. Noh, Kwi-ok, Kwak \& Jung-in (2012). Childhood Education and Care Setting in South Korea. Asian Social Science, 7(6).

15. S. Sabah, H Hammouri (2010). Does subject matter? Estimating the impact of instructional practices and resources on student achievement in science and mathematics: Findings from TIMSS 2007. Evaluation \& Research in Education, 23 (4): 287-299. https://doi.org/10.1080/09500790.2010.509782

16. Seth Kaplan (2012). How Do States Learn?http://www.fragilestates.org/2012/07/31/how-do-states-learn

17. Shanmugaratnam, T (2015). Budget speech 2015: Building our future, strengthening social security. Retrieved

18. Smaali Bouhlila, Donia (2011). The quality of secondary education in the Middle East and North Africa: What can we learn from TIMSS' results? Compare. 41: 327-352. 10.1080/03057925.2010.539887

19. Tan, C., Koh \& Choy, W (2016). The Education System in Singapore in Juszeczyk s (ed). Asian Education System, 129-148, TourAdam Marszalek Publishing House.

20. UNISCO \& the International Bureau of Education, World Data on Education. 7th edition, 2010/11 (P 21). See: http://www.ibe.unesco.org/fileadmin/user upload/Publications/WDE/2010/pdf-versions/Finland.pdf 
المجلة الدولية للدراسـات التربوية والنفسية

International Journal of Educational \& Psychological Studies (EPS)

Journal Homepage: https://www.refaad.com/views/EPSR/Home.aspx

www.refaad.com

ISSN: 2520-4149 (Online) 2520-4130 (Print)

\title{
A comparative study of the international tests (TIMSS) in Singapore and south Korea and the possibility of benefiting from them in the Kingdom of Saudi Arabia
}

\author{
Amani Ahmed M Al-iqali \\ Educational Supervisor, Department of Girls' Education in Jeddah, Kingdom of Saudi Arabia \\ Master's Degree from King Abdulaziz University in Jeddah \\ PhD Researcher at Imam Muhammad bin Saud Islamic University in Riyadh \\ amaniahmad14011@gmail.com
}

Received : 16/6/2021 Revised : 21/7/2021 Accepted :6/9/2021 DOI : https://doi.org/10.31559/EPS2021.10.3.11

Abstract: This research aimed to compare the Trends in International Mathematics and Science Study (TIMSS) in Singapore and South Korea to indicate the extent to which they can be benefited from in the Kingdom of Saudi Arabia. The research also aimed to identifying the theoretical frameworks of the international tests to evaluate Trends in International Mathematics and Science Study (TIMSS) among the fourth and eighth grades of basic education in Singapore and South Korea (the comparison countries) in the light of the forces and factors affecting them, as well as identifying the similarities and differences in the application of the international tests TIMSS and benefiting from them in the Kingdom of Saudi Arabia. To achieve the objectives of the research, the researcher made use of the comparative analytical approach of George Berday with four steps, which is description, interpretation, balancing and comparison to study the application of international tests to evaluate the Trends in International Mathematics and Science Study (TIMSS) for the fourth and eighth grades of basic education in the comparison countries Singapore and South Korea in the light of each of the political, geographical, demographic, cultural, and economic factors, then identifying the similarities and differences in the application of the international study TIMSS between the comparison countries. The research ended with presenting some proposals that can benefit from the experiences of the comparison countries (Singapore and South Korea) and their experience in taking international tests and achieving advanced grades in KSA.

Keywords: Trends in International Mathematics and Science Study; TIMSS; International Study; TIMSS, Singapore; South Korea; Saudi Arabia.

\section{References:}

1. 'bd Alrhmn, Alsyd Ghryb (2019). F'alyt Astkhdam Alanshth Alethra'yh Alqa'mh 'la Almsabqat Alryadyh Aldwlyh Timss Fy Tnmyt B'd Mharat Alebda' Alryady Lda Altlab Alfa'qyn Balmrhlh Althanwyh, Mjlt Klyt Altrbyh: Jam't Bwrs'yd, (28): 495537.

2. 'bd Al'aty, Hsn Albat' (2009). Alt'lym Fy Kwrya Aljnwbyh Afdl 5\% Mn Alkhryjyn Ydrswn Tlab Alabtda'yh, Mjlt Alm'rfh: (164): 20.

3. 'bd Al'al, 'ntr Mhmd Ahmd (2007). Edart Alt'lym Fy Kl Mn Alsyn Wkwrya Aljnwbyh Wmalyzya Wemkanyh Alefadh Mnha Fy Msr. Bhth Ghyr Mnshwr, Jam't Swhaj: Klyt Altrbyh.

4. Al'qaly, Amany, Aljhny, Zhwr (2019). Fa'lyt Brnamj Eshrafy Ystnd Ela Aldrash Aldwlyh TIMSS Fy Tnmyt Mharat Altfkyr Alryady Lda Altalbat Fy Almrhltyn Alabtda'yh Walmtwsth Bmhafzt Jdh. Bhth Mnshwr, Alm'tmr Altas' Bjam't Almlk S'ewd.

5. 'mar, Rdwa Syd Ahmd (2016). Nzam Alhkm Almhly Fy Snghafwrh (www.academi.edu/16691770).

6. Al'nanbh, Ahmd Mhmd (2014). Drash Thlylyh Lwaq' Altjarh Alkharjyh Byn Dwlt Alemarat Al'rbyh Almthdh Wjmhwryh Snghafwrh. Edart Althlyl Walm'lwmat Altjaryh, Wzart Alaqtsad, Abw Zby.

7. Al'nzy, 'bd Al'zyz Rwáf Walms'd, Ahmd Zyd (2018). Waq' Astkhdam Altqnyh Fy Tdrys Alryadyat Llmrhlh Alabtda'yh Fy Mdars Mdynt 'r'r Mn Wjht Nzr Alm'Imyn Walm'Imat. Mjlt Al'lwm Altrbwyh Walnfsyh: 2 (23).

8. 'ysan, Salhh 'bd Allh (2009). Alastratyjyat Alhdythh Fy Tdryb Alm'lmyn Athna' Alkhdmh Tjrbt Snghafwrh. Rsalt Altrbyh: (23).

9. Abw 'ysh, Bsynh Bnt Rshad Bn 'ly (2015). Tswr Mqtrh Lttwyr Mstwa Ada' Tlab Almmlkh Al'rbyh Als'wdyh Fy Al'lwm Walryadyat Fy Dw' Msharkthm Fy Aldrash Aldwlyh Lhma, Mjlt Klyt Altrbyh: Jam't Alazhr, 34 (1): 161-186. 
10. Bdr, Bthynh Mhmd Bn Hmwd (2016). Thlyl Mhtwa Ktab Alryadyat Llsf Alrab' Alabtda'y Balmmlkh Al'rbyh Als'wdyh Wfqa Lmttlbat Drash Altwjhat Aldwlyh Llryadyat Wal'lwm TIMSS , Almjlh Altrbwyh: Alkwyt, 31 (121): 209 -258.

11. Albhyry, Khald (2010). Alt'lym Alasasy Fy Kl Mn Sltnh 'man Wkwrya Aljnwbyh, Drash Mqarnh. Wzart Altrbyh Walt'lym, (30): 54-67.

12. Alblwy, 'ayd 'ly Mhmd (2016). Thlyl Mhtwa Ktab Alryadyat Llsf Alrab' Alabtda'y Fy Almmlkh Al'rbyh Als'wdyh Wfq Mttlbat Aldrash Aldwlyh Llryadyat Wal'lwm TIMSS2011 , Mjlt Jam't Tybh (Al'lwm Altrbwyh): Als'wdyh.

13. Bn 'ly, Bsynh (2015). Tswr Mqtrh Lttwyr Mstwa Ada' Tlab Almmlkh Al'rbyh Als'wdyh Fy Al'lwm Walryadyat Fy Dw' Msharkthm Fy Aldrash Aldwlyh Lhma, Mjlt Klyt Altrbyh: Jam't Alazhr, 34 (162): 161-186.

14. Bwrsly, Nwra Wlyd (2018). Tby't Alsyash Alt'lymyh Fy Almrhlh Althanwyh Fy Kl Mn Snghafwrh Wfnlnda: Thlyl Wtha'q, Almjlh Altrbwyh: Jam't Alkwyt, Mjls Alnshr Al'lmy, 33 (129): 15-64.

15. Aldkhyl, 'zam Mhmd (2014). Nzrh Fy T'lym Aldwl Al'shr Alawa'l Fy Mjal Alt'lym 'br T'lymhm Alasasy. Aldar Al'rbyh Ll'lwm, Nashrwn, Byrwt.

16. Eyshy, Masakw (2006). Alflbyn Wtayland Wsnghafwrh Wbrwma Wkmbwdya Wlarws Mnd Bdayat Alqrn Al'shryn Ela Alhadr (Trjmh: Bthynh Alnasry), Fy (Jwzyf S'ead): Mwsw't Alnsha' Walthqafat Aleslamyh, M'sst Almrah Waldakrh, Alqahrh.

17. Alhbyb, Mhmd Ebrahym (2019). Tqyym Mhtwa Ktab Alryadyat Llsf Alrab' Alabtda'y Fy Almmlkh Al'rbyh Als'wdyh Fy Dw' Mttlbat Drash Altwjhat Aldwlyh Fy Alryadyat Wal'lwm TIMSS 2011, Almjlh Altrbwyh: Jam't Swhaj, 62: 533-575.

18. Alhsan, Amany (2015). Mda Thqyq Mttlbat Mshrw' Altwjhat Aldwlyh Lldrash Fy Ktab Al'lwm Mn Alsf Alawl Ela Alrab' TIMSS-2015 Alryadyat Wal'lwm Alabtda'y Fy Almmlkh Al'rbyh Als'wdyh: Drash Thlylyh. Mjlt Alzrqa' Llbhwth Waldrasat: 15(1): 112-132.

19. Aljndy, Hsn 'wd Hsn Wkhlyl, Ebrahym Bn Alhsyn (2019). Astkhdam Astratyjyh Tdrysyh Qa'mh 'la Albra'h Alryadyh Fy Tnmyh Althsyl Aldrasy Wfqana Llakhtbarat Aldwlyh TIMSS Wtqdyr Aldat Alryady Lda Tlamyd Almrhlh Alabtda'yh, Mjlt Trbwyat Alryadyat: Aljm'yh Almsryh Ltrbwyat Alryadyat. 22 (12): 67-131.

20. Aljrf, Ryma S'd (2004). Alb'd Al'almy Fy Mnahj Aldrasat Alajtma'yh Llmrhlh Althanwyh Fy Snghafwrh (Ndwt Almnahj: Alass Walmntlqat). Klyt Altrbyh, Jam't Almlk S'wd, Alryad, 2.

21. Khlyl, Nbyl S'd (2002). Edart Alt'lym Fy Jmhwryh Kwrya Aljnwbyh Wemkanyh Alefadh Mnha Fy Ttwyr Edart Alt'lym Fy Msr", Mjlt Klyt Altrbyh: 18(2): 34-36.

22. Rshad, Swzy Mhmd (2014). Drash Hwl Dwr Alt'lym Fy Altnmyh: Khbrh Kwrya Aljnwbyh, Mjlt Alnhdh: Klyt Alaqtsad Wal'lwm Alsyasyh, Jam't Alqahrh, 15 (4): 35-60.

23. Alrshydy, Ghazy 'nyzan (2017). Almlamh Almmyzh Lnzam Alt'lym Fy Snghafwrh, Wemkanyh Alefadh Mnha Fy Dwlt Alkwyt: Drash Thlylyh, Mjlt Klyt Altrbyh: Jam't Aleskndryh, 27 (1): 93-134.

24. Alrwyly, Fars Qyad Wal'nzy, Fyad Hamd (2018). Thlyl Mhtwa Mqrr Al'lwm Llsf Althany Almtwst Fy Almmlkh Al'rbyh Als'wdyh Fy Dw' Mttlbat Drash (TIMSS). Mjlt Alhkmh Lldrasat Altrbwyh Walnfsyh: (15).

25. Shhab, Lbny Mhmwd 'bd Alkrym (2019). Mqarnh Lshbkat Mjtm'at Alt'lm Almhnyh Fy Snghafwrh Wenjltra Llefadh Mnha Fy Almdars Almsryh. Jam't Swhaj - Klyt Altrbyh: (65): 639-729.

26. Alshhry, Man' Bn 'ly Alhmydy (2017). Thlyl Mhtwa Mqrrat Alryadyat Balmrhlh Almtwsth Fy Dw' Mttlbat Aldrash Aldwlyh Althalthh Ll'lwm Walryadyat TIMSS, Almjlh Aldwlyh Altrbwyh Almtkhssh: Dar Smat Lldrasat Walabhath, 6(1): 43-64.

27. Alshrbyny, Asamh Esma'yl (2018). Mjtm' Alm'rfh Fy Kl Mn Snghafwrh Walsyn Wkyfyt Alefadh Mnh Fy Jmhwryh Msr Al'rbyh: Drash Mqarnh. Awraq 'ml Alm'tmr Al'lmy Alsnwy Alkhams Wal'shryn Lljm'yh Almsryh Lltrbyh Almqarnh Waledarh Alt'lymyh: Nzm Alt'lym Wmjtm' Alm'rfh, Aljm'yh Almsryh Lltrbyh Almqarnh Waledarh Alt'lymyh, 15-82.

28. Alshmrany, Salh, S'yd Albrsan, Aldwrany, Esma'yl Slamh (2016). Eda'at Hwl Nta'j Dwl Alkhlyj Fy Drash Altwjhat Aldwlyh Fy Alryadyat Wal'lwm 2015 TIMSS. Mrkz Altmyz Albhthy Fy Ttwyr T'lym Alryadyat Wal'lwm, Alryad.

29. Shwn, Yw Fwy (2009). Tqryr Snghafwrh Aldwry Alrab' 'n Atfaqyh Alamm Almthdh Balqda' 'la Jmy' Ashkal Altmyz Dd Almrah. Alamm Almthdh.

30. Tan, Sharlyn (2010). Msarat Syash Alt'lym Fy 'sr Al'wlmh, Shwahd Mn Snghafwrh Wkmbwdya, Mjlt Mstqblyat (Mrkz Mtbw'at Alywnskw), Alqahrh, 4 (4): 713-738. 